\title{
Article \\ Identification of Arvicola terrestris scherman Sperm Antigens for Immune Contraceptive Purposes
}

\author{
Areski Chorfa, Chantal Goubely, Joelle Henry-Berger, Rachel Guiton, Joël R. Drevet*(D) and Fabrice Saez *(D)
}

check for updates

Citation: Chorfa, A.; Goubely, C.; Henry-Berger, J.; Guiton, R.; Drevet, J.R.; Saez, F. Identification of Arvicola terrestris scherman Sperm Antigens for Immune Contraceptive Purposes. Int J. Mol. Sci. 2021, 22, 9965. https:// doi.org/10.3390/ijms22189965

Academic Editor: Jan Tesarik

Received: 20 August 2021

Accepted: 11 September 2021

Published: 15 September 2021

Publisher's Note: MDPI stays neutral with regard to jurisdictional claims in published maps and institutional affiliations.

Copyright: (c) 2021 by the authors. Licensee MDPI, Basel, Switzerland. This article is an open access article distributed under the terms and conditions of the Creative Commons Attribution (CC BY) license (https:// creativecommons.org/licenses/by/ $4.0 /)$.
UMR GReD Institute (Génétique Reproduction \& Développement) CNRS 6293, INSERM U1103, Equipe «Mécanismes de L'infertilité Mâle Post-Testiculaire», Université Clermont Auvergne, 63000 Clermont-Ferrand, France; areski.chorfa@uca.fr (A.C.); chantal.goubely@uca.fr (C.G.); joelle.henry@uca.fr (J.H.-B.); rachel.guiton@uca.fr (R.G.)

* Correspondence: joel.drevet@uca.fr (J.R.D.); fabrice.saez@uca.fr (F.S.); Tel.: +33-4-73-40-74-13 (J.R.D.); +33-4-73-40-76-20 (F.S.)

Abstract: The cyclical proliferation of the wild fossorial rodent Arvicola terrestris scherman (ATS) is critical in mid-mountain ecosystems of several European countries. Our goal is to develop an immunocontraceptive vaccine to control their fertility, as a sustainable alternative to chemical poisons currently used. Indeed, these chemicals cause the death of ATS predators and animals sharing their ecosystem, and current laws progressively limit their use, making the development of a targeted vaccination strategy an interesting and efficient alternative. In order to identify species-specific sperm antigens, male and female ATS received subcutaneous injections of whole ATS spermatozoa to elicit an immune response. The analysis of the immune sera led to the identification of 120 immunogenic proteins of sperm cells. Of these, 15 were strictly sperm-specific and located in different regions of the male gamete. Some of these antigens are proteins involved in molecular events essential to the reproductive process, such as sperm-egg interaction, acrosomal reaction, or sperm motility. This approach not only identified a panel of immunogenic proteins from ATS sperm cells, but also demonstrated that some of these proteins trigger an immune response in both male and female ATS. These spermatic antigens are good candidates for the development of a contraceptive vaccine.

Keywords: sperm cells; contraceptive vaccine; wild rodent

\section{Introduction}

The terrestrial vole, also known as Arvicola terrestris Scherman (ATS), is a fossorial rodent living in underground tunnels in mid-mountain regions generally located between 400 and $1500 \mathrm{~m}$ above sea level [1]. The proliferation of this rodent shows cyclical variations over a period of about 5 to 6 years, with densities ranging from 50-100 animals/hectare to more than 1000 during outbreaks [2,3]. The excessive cyclical proliferation and expansion of ATS colonization areas, since the 1970s, mainly in mid-mountain agronomic and tourist ecosystems, is an increasingly important problem with strong environmental and economic impacts [4-6]. At high densities, ATS affects the botanical composition of grasslands, causing the regression of legumes and the increase of poor-quality grass and undesirable plants. On cultivated plots, ATS can damage cereal crops, orchards, vegetable gardens, vineyards, forests, and ornamental gardens $[7,8]$. One consequence of ATS activity on grassland areas is the presence of mounds that facilitate the ingestion of soil by grazing animals. This leads to an alteration of milk quality characterized by a reduction in protein content and contamination by butyric bacteria. ATS outbreaks are also a public health risk because they are vectors of zoonosis. There is a strong relationship between ATS density and the risk factor for alveolar echinococcosis [9]. Human alveolar echinococcosis is a serious parasitic disease caused by the larva of a flatworm, Echinococcus multilocularis, mainly characterized by hepatic development in a tumorous form, and with no treatment currently available. 
Current strategies to control ATS populations are dominated by lethal procedures, such as physical trapping and chemical poisoning with baits (wheat, carrot) soaked with the anticoagulant bromadiolone [10]. Although these approaches are effective, they are neither economically viable (trapping) nor environmentally acceptable anymore (chemical control). Indeed, the non-specific nature of chemical control means that collateral damage to off-target fauna (animals with similar diets or predators of ATS, such as wild boars, foxes, ermines, weasels, birds of prey, and even cats and dogs) is significant [11,12]. Moreover, although chemical control is performed in a reasoned manner (monitoring of outbreaks, treatment under administrative order, controlled distribution of baits, abandonment of treatments in periods or areas of high densities, etc.) the contamination of ecosystems (groundwater, rivers, sewage treatment plants, etc.) by bromadiolone is a new health risk for the public and wildlife [13]. Recently, in France, the National Agency for Food, Environmental, and Occupational Health and Safety (ANSES) stated that the use of this chemical does not exclude "an unacceptable risk to aquatic organisms, terrestrial vertebrates and groundwater contamination" (AMM no 9800526). This situation urges the development of alternative strategies to fight against the outbreaks of this harmful rodent.

In this context, immunocontraception is an interesting option to limit the reproduction of ATS. Immunocontraception involves the administration of a vaccine that induces an adaptive immune response, resulting in subfertility or sterility. Contraceptive vaccines have been used and proven effective in many situations to control the fertility of captive and/or semi-captive wild or domestic animal populations, including horses [14], deer [15,16], squirrels [17], marsupials [18], and African elephants [19]. Briefly, three strategies can be used to achieve vaccine contraception: a post-fertilization strategy by interfering with fetal implantation via a GnRH vaccine (gonadotrophin-releasing hormone) and two prefertilization strategies that aim to limit gametic interaction by interfering either with the female gamete or with the male gamete. Anti-GnRH and anti-ZP3 vaccines, with ZP3 being one of the zona pellucida proteins surrounding the oocyte in mammals, are effective in inducing immune contraception $[20,21]$. These two vaccine approaches, however, present a major pitfall in the context of our interest, which is that they do not allow species specificity given the good sequence conservation of GnRH and ZP3 in mammals. Only the vaccine strategy directed against spermatic antigens makes it possible to envisage a high level of species specificity due to the large number of potential spermatic antigenic targets and the inter-species sequence polymorphism [22-24].

While it is rather generally intuitive that sperm antigens can be recognized as nonself by the immune system of female animals, theoretically they should also cause the production of anti-sperm antibodies in males. Indeed, spermatozoa are produced at puberty, long after the repertoire of the self has been established. They are thus considered as non-self even for the male who produces them. The fact that sperm antigens are good triggers of immune responses has been clearly demonstrated by the observation that $70 \%$ of men who have undergone a vasectomy develop anti-sperm antibodies or ASA [25-27], which often compromises the restoration of fertility in the case of a vaso-vasostomy. These ASA result from the presentation of sperm antigens to the host immune system due to the increased permeability of the blood-testis-epidididymal barriers, a consequence of vasectomy [28]. In addition, ASA have been identified in some human infertile cases [29,30], where they were shown to cause infertility by inhibiting spermatozoa/oocyte binding, reducing sperm motility, reducing sperm penetration into cervical mucus, and altering capacitation and/or acrosomal reaction.

In this context, immunocontraception studies carried out to date, on different models, used either whole spermatozoa or specific individual sperm antigens. Injection of whole spermatozoa as immunogens was performed in tammar wallabies [31], mice [32], rabbits [33,34], and dogs [35]. However, in these studies, the determination of the sperm antigens triggering the immune response was not conducted, only antibody production and the effects on fertility were described. In rodent models, several sperm antigens (proteins and/or peptides) were studied separately as potential targets for immunocontraception. 
Even though efficient immune responses and decreased fertility were obtained when using FA1 [36], CRISP1 [37], SPAG9 [38], or tNASP [39], no further studies were conducted, to our knowledge, to control the population expansion of wild (or domestic) species with these immunogens.

In the present work, we used a whole spermatozoa immunization strategy to identify specific ATS sperm antigens for the future development of a contraceptive vaccine.

\section{Results}

\subsection{Immunoglobulin Detection and Western Blot}

Amido black staining was used to reveal the different immunoglobulins present in the pre-immune and immune sera of male and female voles after subcutaneous immunization with whole spermatozoa (Figure 1). Comparison of the pre-immune (Pi) and immune (i) sera for each immunized animal showed a clear increase in the corresponding IgM-IgA bands for four males (1, 2, 4, and 5; Figure 1A) and five females (1 to 5; Figure 1C). The $\mathrm{IgG}$ appeared as a smear (pattern that extended from the loading slot to the IgM band) that increased in immune sera, compared to pre-immune sera, especially for males 1, 2, 4, and 5 and for females 1, 2 and 4 to $6\left(^{*}\right.$ in Figure $\left.1 \mathrm{~A}, \mathrm{C}\right)$.
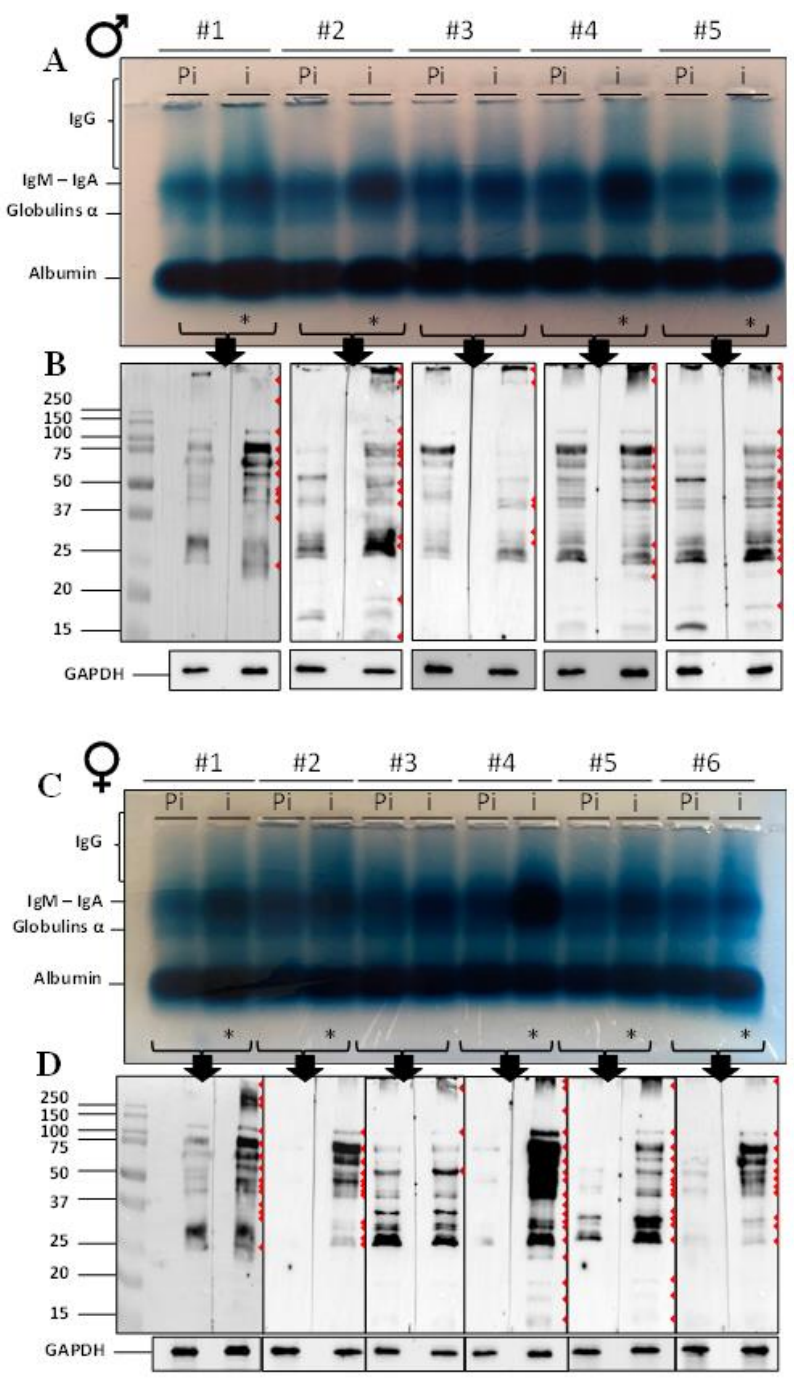

Figure 1. Characterization of serum antibody production after immunization in male and female ATS. $(\mathrm{A}, \mathrm{C})$ Amido black staining. Albumin, alpha globulins, IgM-IgA and IgG profiles in the pre-immune (Pi) and immune sera (i) of five male and six female ATS, respectively, were detected in an agarose gel 
stained with amido black. The stars $\left(^{*}\right)$ indicate a strong increase of globulin levels after immunization. (B,D) Western blots against ATS sperm proteins. Thirty $\mu \mathrm{g}$ of soluble sperm (spz) proteins from ATS were loaded on $12 \%$ SDS-PAGE gels. The pre-immune (Pi) and immune (i) sera from five male and six female ATS, respectively, were used as primary antibodies. The red arrowheads indicate bands differing between pre-immune and immune sera (presence and/or intensity) of the same individual. An anti-GAPDH antibody was used to indicate the similar total protein load in each well (lower panels). Each blot was performed at least twice and each serum was used to probe the spz proteins extracted from at least two different animals.

To verify that anti-sperm IgG were produced in response to immunizations, we examined each serum (pre-immune and immune, $\mathrm{Pi}$ and $\mathrm{i}$, respectively) by Western blotting against proteins extracted from non-immunized ATS spermatozoa (Figure 1B,D). The detection of anti-sperm antibodies in voles was made possible by the generation of a secondary ATS-specific anti-IgG antibody conjugated to HRP (Figure S1). As can be seen in Figure 1B,D, several discrete bands were detected (red arrowheads). In most samples, whether male or female, a greater number of bands and higher intensity bands were detected in immune sera compared to pre-immune sera. This was particularly true for females and less true for males. It was also clear that female immune sera have a much higher reactivity than male immune sera when comparing Figure 1B with Figure 1D. Few animals appeared to be unreactive to immunizations. This was the case for male \#3 and female \#3, for which there were no obvious differences when comparing pre-immune and immune sera.

For further identification of the ATS sperm antigens that provoked the immune responses and the generation of ASA, we pooled the sera of the responding animals. The same was done with pre-immune sera. Two-dimensional electrophoresis (2D) was used to analyze pooled pre-immune and immune sera from male and female ATS (Figure 2). As revealed by 1D analysis (Figure 1), pre-immune sera contained antibodies directed against sperm proteins (Figure 2A,C). The immunization triggered a higher reactivity for ATS sperm proteins in both males and females (blots with immune sera in Figure 2B,D). Among the complex patterns of revealed proteins, red boxed areas on the 2D gels point out protein spots with a certain level of sex specificity, thus showing that males and females put up a different immune response when immunized against whole ATS spermatozoa.

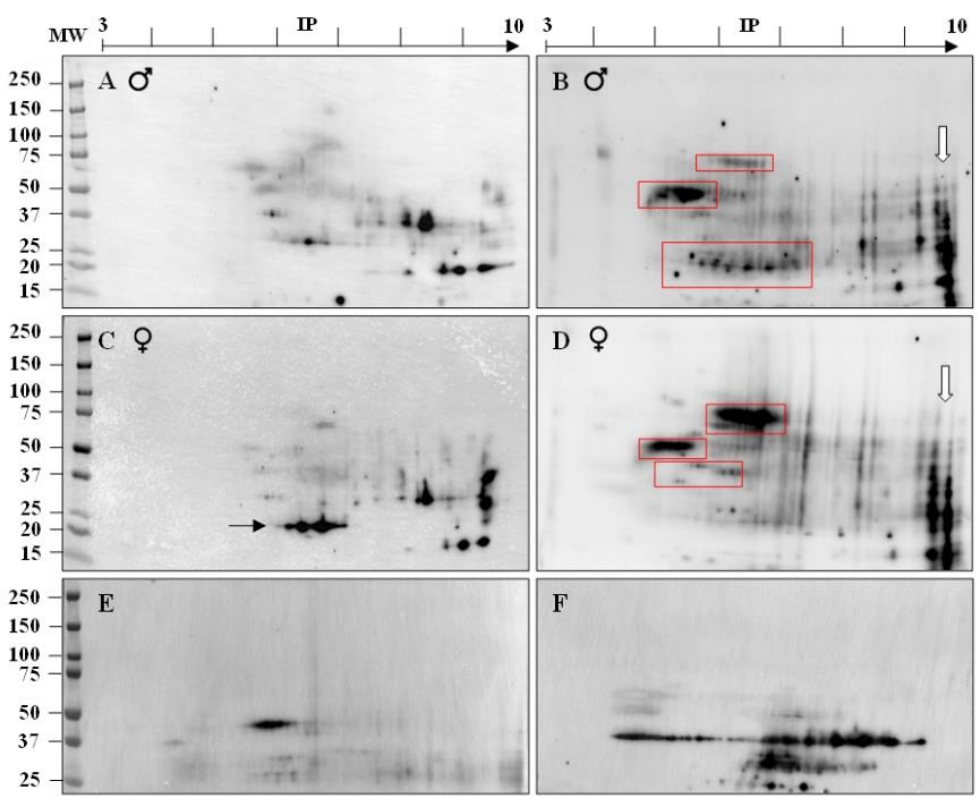

Figure 2. Two-dimensional characterization of ATS sperm proteins recognized by ASA. Western blots showing the reactivity of pre-immune $(\mathbf{A}, \mathbf{C})$ and immune $(\mathbf{B}, \mathbf{D})$ sera (pools of sera from 5 male and 6 female ATS, respectively) against ATS sperm proteins separated by two-dimensional electrophoresis. 
A black arrow indicates a small group of $20 \mathrm{kDa}$ spots specifically present in female pre-immune sera (C), although in both cases some antibodies recognized ATS spz proteins (A,C). The red boxes indicate three groups of spots specifically detected by male immune sera (B) and three groups of spots specifically detected by female immune sera (D). The white arrows (B,D) show two groups of very basic spots (IP from 9 to 10) and MW ranging from 12 to $60 \mathrm{kDa}$ detected when blotting with either male or female sera. Positive controls showing blots against the beta-actin (E) and GAPDH (F) proteins attest the good migration of total extracts of ATS sperm proteins in our conditions. Each blot was performed at least twice and each serum was used to probe the spz proteins of at least two different animals.

\subsection{ASA Do Target ATS Sperm Surface Proteins}

To visualize which regions of the ATS spermatozoa carry the antigens that provoked the generation of ASA, we used immunocytochemistry and confocal microscopy (Figure 3). Both pooled immune sera from males and pooled immune sera from females were tested and are presented, respectively, in Figure $3 \mathrm{~A}-\mathrm{C}$ and Figure 3B-D. To better localize the different spermatozoa compartments, a Mitotracker probe (Figure 3A,B) and an Alexa Fluor 488 lectin-PNA probe (Figure 3C,D) were used to, respectively, show the spermatozoa mitochondria-containing midpiece and the sperm head acrosome region. Merged images are provided as well as $3 \mathrm{D}$ reconstructions, as allowed by the confocal microscopy technique used. It is interesting to point out that the male immune serum mainly recognized antigens associated with the sperm head and neck (junction flagellum-head) regions, as well as with the terminal part of the flagellum (Figure 3A). In addition to the sperm cell parts recognized by the male immune serum, the female immune serum also distinctly recognized antigens associated with the sperm midpiece, clearly co-localizing with mitochondria. The confocal $3 \mathrm{D}$ visualization of sperm head images (lower panels of Figure 3C,D) merging the acrosome lectin-PNA detection and the ATS immune sera detection suggested that both male and female immune sera showed reactivity with antigens located in the acrosomal domain and with antigens most likely located in the sperm plasma membrane.

\subsection{Identification of Immunogenic ATS Sperm Proteins by Proteomic Analysis}

To identify the ATS sperm antigens recognized by the ASA, we proceeded with an immunoprecipitation strategy (Figure S2) coupled with quantitative mass spectrometry analysis. As the ATS genomic sequence was not yet available, we used the phylogenetically closest genome present in databases, which was that of the Microtus ochrogaster (Prairie vole). Overall, 114 different protein targets were identified as differentially pulled down when the immune serum was compared to the pre-immune serum (Table S1a,b). For six of these proteins, the identified peptides matched with a somatic protein and a sperm-specific isoform. The six isoforms were added to the list (Table S2), raising the total number to 120 .

The 120 proteins were classified following several criteria. Table 1 presents the proteins involved in essential steps of the fertilization process, including sperm-egg interaction, zona pellucida penetration, sperm capacitation, and acrosomal reaction. A fifth group, entitled "sperm parts", contains proteins located in specific subcellular compartments of the spermatozoa, including the nucleus and terminal, and the main and intermediate segments of the flagellum. The proteins involved in metabolic energy processes, located in the mitochondria and chaperones, are listed in the last three groups of this table. As already shown by the immunolocalization of ASA targets on ATS spermatozoa (Figure 3), mitochondrial proteins were much more targeted by ASA generated in females than in males. A certain number of proteins could be gathered in three particular groups, as presented in Table 2 . Ten proteins belong to a family called moonlighting proteins, which are known for bearing peculiarities in the reproductive function (see the discussion section). Fourteen proteins could be related to phenotypes specific to sexual organs when their gene expression is invalidated, and among those 11 are strictly present in spermatozoa ( ${ }^{*}$ in Table 2). Finally, 29 proteins have been previously reported as being part of the epididymosomes, exosomes secreted by the epididymal epithelium and involved in the 
spermatozoa post-testicular maturation process. Some of the identified proteins have functions related to housekeeping processes and/or non-reproductive functions (Table 3) that could be subclassified into DNA/RNA binding, complement activation, cytoskeletal proteins, lipid metabolism, and a final category called "others", which includes proteins whose function is not included elsewhere.

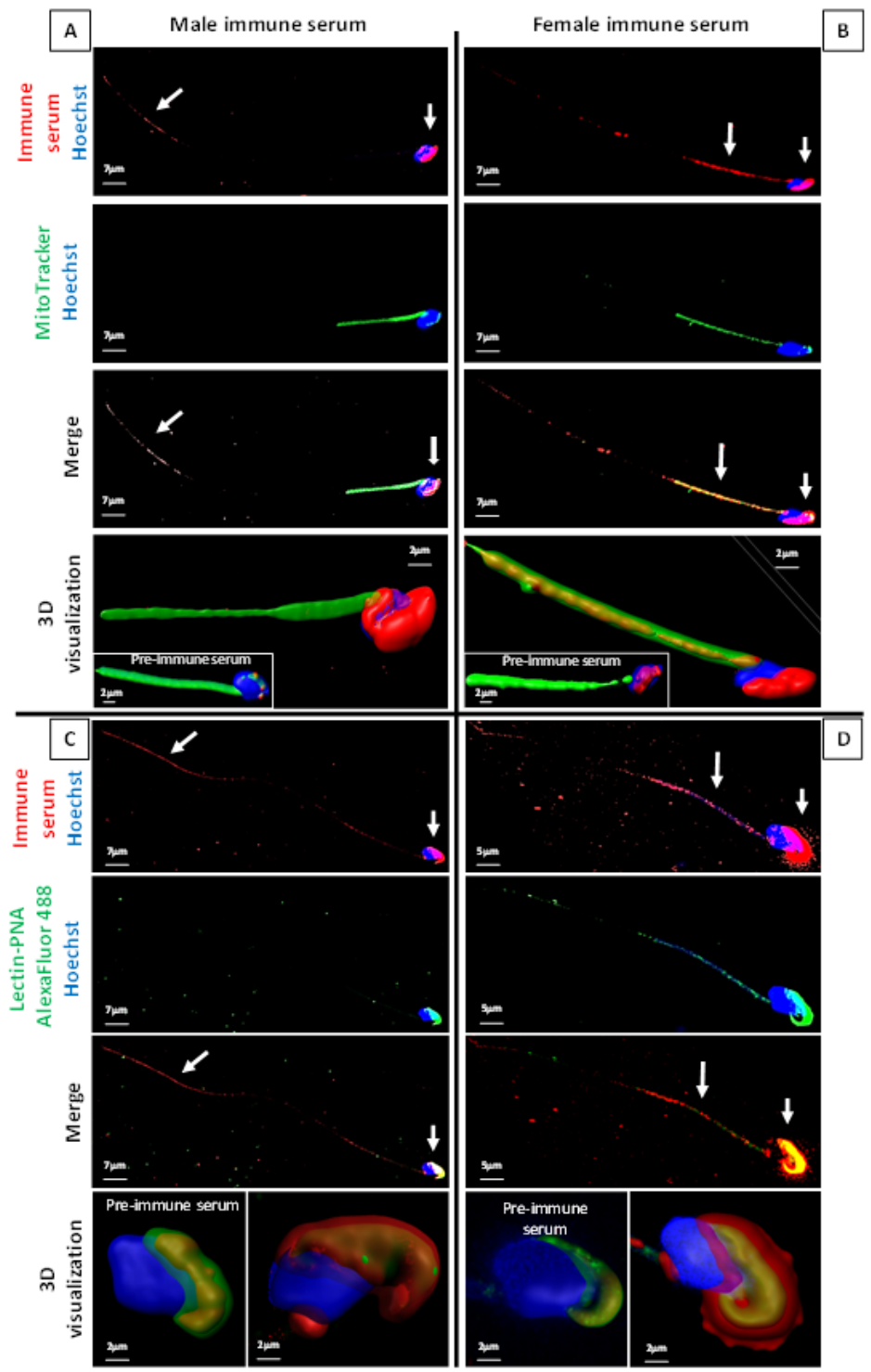

Figure 3. Cellular localization of the proteins recognized by ASA from male and female sera. $(\mathbf{A}, \mathbf{B})$ Fresh ATS spermatozoa were triple labelled with the pooled male and female ATS immune sera (red), the Mitotracker probe (green), and Hoechst 33342 (blue). Confocal images were processed using Imaris software to obtain a 3D reconstruction of the spermatozoa (lower panels). A focus was made on the middle part of the flagellum and the sperm head. The green staining was made $50 \%$ transparent to determine the cellular location of the red label. The white arrows indicate the red labelling of interest, i.e., antigens recognized by ASA. Male immune sera recognized proteins on the surface of the flagellum tip (final piece), a small part of the principal piece, the base of the flagellum (centriole), the head, the acrosome, and very weakly on the intermediate piece, whereas ASA contained in the pool of female immune sera recognized proteins of the intermediate piece of the flagellum, the flagellum base (centriole), the acrosome, and weakly on the flagellum tip and the principal piece. Images obtained with male and female pre-immune sera were processed the same way (insets in the 3D visualization images) and showed weak staining on the acrosome for both male 
and female, slightly more intense with female pre-immune sera (in accordance with the Western blots and 2D electrophoresis shown in Figures 1 and 2). (C,D) Fresh ATS spermatozoa were triple labelled with the immune serum pool of the male and female ATS (red), the lectin-PNA-Alexa Fluor 488 Conjugated (green), and the Hoechst 33342 (blue). The green marker in the pre-immune serum inset and the red marker in the immune serum pictures were made $50 \%$ transparent to determine the external cell location of the markers. A focus was made on the acrosome. White arrows indicate the red labelling of interest (antigens recognized by the ASA). The pictures shown in this figure are representative of five experiments performed under these conditions. We used the same pre-immune and immune sera as for Figures 1 and 2. Each pool of sera was tested at least three times to stain spz from at least two different non-immunized animals.

Table 1. Proteins recognized by ASA, produced by male and female ATS, and identified by LC-MS/MS. The classification was made according to their function in the reproductive process or their subcellular location.

\begin{tabular}{|c|c|c|c|c|c|c|c|}
\hline Protein Name & $\begin{array}{l}\text { UniProtKB } \\
\text { IDs }\end{array}$ & MW (Da) & Th.Ip & mFC Male & mFC Female & $\begin{array}{c}\text { No. of } \\
\text { Peptides } \\
\text { (\% Coverage) }\end{array}$ & $\begin{array}{c}\text { Mascot } \\
\text { Score }\end{array}$ \\
\hline \multicolumn{8}{|c|}{ Sperm-egg interaction } \\
\hline ALDOA & P05064 & 37,817 & 8.30 & 3.75 & 4.33 & $8(43.20)$ & 497.32 \\
\hline HSPA1L * & P16627 & 70,981 & 5.76 & 6.83 & 25.86 & $2(7.80)$ & 234.52 \\
\hline ССТ3 & P80318 & 61,265 & 6.10 & 5.86 & 89.02 & $2(3.49)$ & 79.20 \\
\hline ССТ8 & P42932 & 60,116 & 5.42 & 1.52 & 1.81 & $2(4.38)$ & 123.39 \\
\hline $\mathrm{ZPBP} *$ & Q62522 & 42,640 & 9.43 & 2.83 & 6.57 & $7(15.26)$ & 386.51 \\
\hline $\mathrm{ZPBP} 2 *$ & Q6X786 & 42,640 & 8.04 & 2.83 & 6.57 & $7(22.92)$ & 580.50 \\
\hline HSPD1 (HSP60) & P63038 & 55,970 & 5.70 & 1.79 & 6.83 & $7(19.01)$ & 397.55 \\
\hline \multicolumn{8}{|c|}{ Penetration of zona pellucida } \\
\hline HEXB & P20060 & 54,911 & 6.29 & 1.96 & 4.07 & $5(12.82)$ & 319.44 \\
\hline $\mathrm{ACR} *$ & P23578 & 50,286 & 9.26 & 1.65 & 3.34 & $6(18.88)$ & 468.93 \\
\hline \multicolumn{8}{|c|}{ Sperm capacitation } \\
\hline PEBP1 & P70296 & 21,024 & 7.01 & 3.10 & 5.77 & $3(28.33)$ & 198.37 \\
\hline AKAP3 * & O88987 & 94,787 & 5.84 & 3.52 & 12.72 & $3(3.20)$ & 169.17 \\
\hline YWHAZ & P63101 & 27,898 & 4.73 & 1.27 & 2.65 & $7(30.20)$ & 503.69 \\
\hline PRKACA & P05132 & 40,713 & 8.84 & 0.95 & 0.49 & $6(14.29)$ & 322.06 \\
\hline ROPN1* & Q9ESG2 & 24,123 & 5.52 & 1.51 & 7.34 & $3(18.90)$ & 233.78 \\
\hline \multicolumn{8}{|c|}{ Acrosomal reaction } \\
\hline CALR & P14211 & 48,159 & 4.29 & 1.76 & 3.41 & $11(28.92)$ & 864.52 \\
\hline PDIA3 & P27773 & 57,052 & 5.98 & 1.94 & 5.29 & $12(26.14)$ & 770.66 \\
\hline $\mathrm{ACR} *$ & P23578 & 50,286 & 9.26 & 1.65 & 3.34 & $6(18.88)$ & 468.93 \\
\hline HEXB & P07686 & 54,911 & 6.29 & 1.96 & 4.07 & $5(12.82)$ & 319.44 \\
\hline AKAP3 * & O88987 & 94,787 & 5.84 & 3.52 & 12.72 & $3(3.20)$ & 169.17 \\
\hline \multicolumn{8}{|c|}{ Sperm part } \\
\hline ALDOA & P05064 & 37,817 & 8.30 & 3.75 & 4.33 & $8(43.20)$ & 497.32 \\
\hline NUP210L * & Q9D2F7 & 202,450 & 7.15 & 5.64 & 6.87 & $33(17.50)$ & 2493.12 \\
\hline PRKAR2A & P12367 & 45,817 & 4.96 & 1.52 & 3.41 & $3(7.37)$ & 167.54 \\
\hline ODF1 * & Q61999 & 29,282 & 8.46 & 1.57 & 2.01 & $23(53.31)$ & 1421.42 \\
\hline GAPDHS * & Q64467 & 35,936 & 8.39 & 1.51 & 2.86 & $8(9.36)$ & 178.10 \\
\hline PGK2 * & P09041 & 27,881 & 8.74 & 1.33 & 2.77 & $4(6.95)$ & 233.10 \\
\hline OAZ3* & Q9R109 & 26,958 & 6.38 & 8.10 & 20.86 & $2(7.69)$ & 202.45 \\
\hline AKAP3 * & O88987 & 94,787 & 5.84 & 3.52 & 12.72 & $3(3.20)$ & 169.17 \\
\hline DYNLL2 & Q9D0M5 & 10,457 & 6.81 & 2.79 & 4.45 & $2(27)$ & 199.68 \\
\hline ROPN1 * & Q9ESG2 & 24,123 & 5.52 & 1.51 & 7.34 & $3(18.90)$ & 233.78 \\
\hline PRKACA & P05132 & 40,713 & 8.84 & 1.06 & 2.05 & $6(14.29)$ & 322.06 \\
\hline \multicolumn{8}{|c|}{ Carbohydrate metabolism/Glycolysis and Gluconeogenesis } \\
\hline ALDOA & P05064 & 37,817 & 8.30 & 3.75 & 4.33 & $8(43.20)$ & 497.32 \\
\hline ACO2 & Q99KI0 & 86,107 & 7.36 & 1.68 & 3.84 & $14(21.50)$ & 1013.27 \\
\hline GAPDH & P16858 & 35,936 & 8.57 & 1.51 & 2.86 & $8(31.23)$ & 594.17 \\
\hline PGK1 & P09411 & 27,881 & 8.30 & 1.33 & 2.77 & $4(11.37)$ & 381.29 \\
\hline
\end{tabular}


Table 1. Cont.

\begin{tabular}{|c|c|c|c|c|c|c|c|}
\hline Protein Name & $\begin{array}{c}\text { UniProtKB } \\
\text { IDs }\end{array}$ & MW (Da) & Th.Ip & mFC Male & mFC Female & $\begin{array}{c}\text { No. of } \\
\text { Peptides } \\
\text { (\% Coverage) }\end{array}$ & $\begin{array}{c}\text { Mascot } \\
\text { Score }\end{array}$ \\
\hline PGK2 * & P09041 & 27,881 & 8.74 & 1.33 & 2.77 & $4(6.95)$ & 233.10 \\
\hline $\mathrm{MDH} 2$ & P08249 & 36,045 & 8.92 & 2.78 & 7.06 & $18(64)$ & 1260.95 \\
\hline CS & Q9CZU6 & 52,010 & 8.45 & 3.57 & 7.15 & $8(21.72)$ & 699.94 \\
\hline ENO1 & P17182 & 47,602 & 7.01 & 1.86 & 2.40 & $9(23.04)$ & 511.79 \\
\hline GPI1 (G6PI) & P06745 & 62,986 & 8.42 & 2.07 & 3.05 & $4(9.32)$ & 245.83 \\
\hline SUCLA2 & Q9Z2I9 & 50,481 & 7.05 & 1.32 & 2.22 & $7(33.81)$ & 803.25 \\
\hline MTHFD1L & Q3V3R1 & 105,743 & 8.32 & 3.81 & 6.45 & $2(3.10)$ & 132.20 \\
\hline LDHC * & P00342 & 28,302 & 7.08 & 1.30 & 0.83 & $3(17.76)$ & 323.87 \\
\hline HK3 & Q3TRM8 & 102,184 & 5.23 & 0.39 & 7.61 & $3(3.15)$ & 163.23 \\
\hline \multicolumn{8}{|c|}{ Energy metabolism } \\
\hline PRDX5 & P99029 & 20,423 & 6.00 & 1.91 & 4.29 & $5(17.60)$ & 313.59 \\
\hline CAR1 & P13634 & 28,550 & 6.59 & 1.72 & 3.44 & $9(52.17)$ & 686.90 \\
\hline CAR2 & P00920 & 29,294 & 6.87 & 1.11 & 2.21 & $4(17.31)$ & 233.50 \\
\hline SDHA & Q8K2B3 & 73,414 & 7.06 & 1.49 & 5.47 & $7(11)$ & 393.12 \\
\hline ATP5B & P56480 & 25,127 & 5.26 & 1.27 & 2.67 & $15(25.39)$ & 1084.34 \\
\hline ATP5F1 & Q9CQQ7 & 10,909 & 9.37 & 0.97 & 1.87 & $2(7.11)$ & 111.97 \\
\hline $\mathrm{COX} 2$ & P00405 & 26,025 & 4.67 & 0.96 & 2.01 & $5(16.30)$ & 311.67 \\
\hline COX4I1 & P19783 & 10,899 & 9.52 & 0.78 & 1.90 & $6(41.30)$ & 357.12 \\
\hline ATP5A1 & Q03265 & 58,502 & 9.16 & 2.47 & 5.22 & $14(25.28)$ & 1072.18 \\
\hline \multicolumn{8}{|c|}{ Mitochondrial protein } \\
\hline PRDX3 & P20108 & 28,428 & 7.68 & 2.07 & 4.46 & $2(7.66)$ & 115.88 \\
\hline MTIF2 & Q91YJ5 & 10,909 & 6.71 & 2.82 & 7.30 & $7(26.91)$ & 488.06 \\
\hline $\mathrm{COX} 2$ & P00405 & 26,025 & 4.67 & 0.96 & 2.01 & $5(16.30)$ & 311.67 \\
\hline SUCLA2 & Q9Z2I9 & 50,481 & 7.05 & 1.32 & 2.22 & $7(33.81)$ & 803.25 \\
\hline DIABLO & Q9JIQ3 & 26,705 & 5.68 & 2.95 & 404.15 & $2(8.09)$ & 83.35 \\
\hline $\mathrm{CHDH}$ & Q8BJ64 & 67020 & 8.57 & 21.01 & 20.77 & $3(4.86)$ & 164.31 \\
\hline SDHA & Q8K2B3 & 73,414 & 7.06 & 1.49 & 5.47 & $7(11)$ & 393.12 \\
\hline ATP5B & P56480 & 25,127 & 5.26 & 1.27 & 2.67 & 15 (25.39) & 1084.34 \\
\hline ATP5F1 & Q9CQQ7 & 10,909 & 9.37 & 0.97 & 1.87 & $2(7.11)$ & 111.97 \\
\hline COX4I1 & P19783 & 10,899 & 9.52 & 0.78 & 1.90 & $6(41.30)$ & 357.12 \\
\hline COX6B2 & Q80ZN9 & 10,835 & 9.21 & 0.85 & 1.58 & $2(23.86)$ & 100.88 \\
\hline NIPSNAP3B & Q9CQE1 & 28,368 & 9.21 & 0.77 & 1.77 & $3(22.84)$ & 213.10 \\
\hline HSPA1L * & P16627 & 70,981 & 5.76 & 6.83 & 25.86 & $2(7.80)$ & 234.52 \\
\hline HSPD1 (HSP60) & P63038 & 55,970 & 5.70 & 1.79 & 6.83 & $7(19.01)$ & 397.55 \\
\hline ATPIF1 & O35143 & 12,255 & 4.82 & 2.91 & 19.66 & $2(17.76)$ & 105.38 \\
\hline $\mathrm{CYCT}^{*}$ & P00015 & 11,654 & 9.54 & 2.56 & 10.67 & $2(27.62)$ & 776.30 \\
\hline CYCS & P62897 & 11,654 & 9.54 & 2.56 & 10.67 & $2(8.92)$ & 250.71 \\
\hline ATP5A1 & Q03265 & 58,502 & 9.16 & 2.47 & 5.22 & $14(25.28)$ & 1072.18 \\
\hline \multicolumn{8}{|c|}{ Chaperones } \\
\hline $\begin{array}{c}\text { HSPA5 } \\
\text { (GR78/BIP) }\end{array}$ & P20029 & 72,606 & 5.07 & 1.99 & 4.19 & 21 (31.76) & 1701.29 \\
\hline HSC70 (HSPA8) & P63017 & 71,069 & 5.37 & 3.99 & 4.49 & $5(16.10)$ & 520.24 \\
\hline HSPA1L * & P16627 & 70,981 & 5.76 & 6.83 & 25.86 & $2(7.80)$ & 234.52 \\
\hline HSPD1 (HSP60) & P63038 & 55,970 & 5.70 & 1.79 & 6.83 & $7(19.01)$ & 397.55 \\
\hline HSP90B1 & P08113 & 92,865 & 4.76 & 1.19 & 1.95 & $16(31.49)$ & 1123.06 \\
\hline
\end{tabular}

The UniProtKb ID, molecular weight (MW), and theoretical isoelectrical point (Th.Ip) are indicated for each protein. The number of peptides and the percentage of coverage, as well as the mascot score are also indicated. For the mascot score, only the peptides for which the score was greater than or equal to that of a validation with less than $1 \%$ false positive (FDR 1\%) were retained. The mean fold change $(\mathrm{mFC})$ obtained from male and female samples is reported. The stars $\left(^{*}\right)$ indicate proteins strictly expressed in spermatozoa. 
Table 2. Proteins recognized by ASA belonging to three special categories: moonlighting proteins, proteins giving a phenotype limited only to the sexual organs when the expression of their gene is invalidated, and proteins contained in the epididymosomes.

\begin{tabular}{|c|c|c|c|c|c|c|c|}
\hline Protein Name & $\begin{array}{l}\text { UniProtKB } \\
\text { IDs }\end{array}$ & MW (Da) & Th.Ip & mFc Male & mFc Female & $\begin{array}{c}\text { No. of } \\
\text { Peptides (\% } \\
\text { Coverage) }\end{array}$ & $\begin{array}{c}\text { Mascot } \\
\text { Score }\end{array}$ \\
\hline \multicolumn{8}{|c|}{ Moonlighting proteins } \\
\hline PGK1 & P09411 & 27,881 & 8.30 & 1.33 & 2.77 & $4(11.37)$ & 381.29 \\
\hline PGK2 * & P09041 & 27,881 & 8.74 & 1.33 & 2.77 & $4(6.95)$ & 233.10 \\
\hline GAPDH & P16858 & 35,936 & 8.57 & 1.51 & 2.86 & $8(31.23)$ & 594.17 \\
\hline $\mathrm{ACO} 2$ & Q99KI0 & 86,107 & 7.36 & 1.68 & 3.84 & $14(21.5)$ & 1013.27 \\
\hline ALDOA & P05064 & 37,817 & 8.30 & 3.75 & 4.33 & $8(43.20)$ & 497.32 \\
\hline ODF1 * & Q61999 & 29,282 & 8.46 & 1.57 & 2.01 & $23(53.31)$ & 1421.42 \\
\hline HSPA5 & P20029 & 72,606 & 5.07 & 1.99 & 4.19 & $21(31.76)$ & 1701.29 \\
\hline $\mathrm{ACR} *$ & P23578 & 50,286 & 9.26 & 1.65 & 3.34 & $6(18.88)$ & 468.93 \\
\hline ENO1 & P17182 & 47,602 & 7.01 & 1.86 & 2.40 & $9(23.04)$ & 511.79 \\
\hline HSPD1 (HSP60) & P63038 & 55,970 & 5.70 & 1.79 & 6.83 & $7(19.01)$ & 397.55 \\
\hline \multicolumn{8}{|c|}{ Phenotype limited only to sexual organs when the gene expression is invalidated } \\
\hline NUP210L * & Q9D2F7 & 202,450 & 7.15 & 5.64 & 6.87 & $33(17.50)$ & 2493.12 \\
\hline PGK1 & P09411 & 27,881 & 8.30 & 1.33 & 2.77 & $4(11.37)$ & 381.29 \\
\hline PGK2 * & P09041 & 27,881 & 8.74 & 1.33 & 2.77 & $4(6.95)$ & 233.10 \\
\hline ODF1 * & Q61999 & 29,282 & 8.46 & 1.57 & 2.01 & $23(53.31)$ & 1421.42 \\
\hline GAPDHS * & Q64467 & 35,936 & 8.39 & 1.51 & 2.86 & $8(9.36)$ & 178.10 \\
\hline ACR * & P23578 & 50,286 & 9.26 & 1.65 & 3.34 & $6(18.88)$ & 468.93 \\
\hline AKAP3 * & O88987 & 94,787 & 5.84 & 3.52 & 12.72 & $3(3.20)$ & 169.17 \\
\hline OAZ3 * & Q9R109 & 26,958 & 6.38 & 8.10 & 20.86 & $2(7.69)$ & 202.45 \\
\hline HSPA1L * & P16627 & 70,981 & 5.76 & 6.83 & 25.86 & $2(7.80)$ & 234.52 \\
\hline $\mathrm{ZPBP} *$ & Q62522 & 42,640 & 9.43 & 2.83 & 6.57 & $7(15.26)$ & 386.51 \\
\hline $\mathrm{ZPBP2} \mathrm{*}$ & Q6X786 & 42,640 & 8.04 & 2.83 & 6.57 & $7(22.92)$ & 580.50 \\
\hline $\mathrm{CHDH}$ & Q8BJ64 & 67,020 & 8.57 & 21.01 & 20.77 & $3(4.86)$ & 164.31 \\
\hline ROPN1 * & Q9ESG2 & 24,123 & 5.52 & 1.51 & 7.34 & $3(18.90)$ & 233.78 \\
\hline PRKACA & P05132 & 40,713 & 8.84 & 0.95 & 0.49 & $6(14.29)$ & 322.06 \\
\hline \multicolumn{8}{|c|}{ Epididymosomes } \\
\hline HSC70 (HSPA8) & P63017 & 71,069 & 5.37 & 3.99 & 4.49 & $5(16.10)$ & 520.24 \\
\hline CAR1 & P13634 & 28,550 & 6.59 & 1.72 & 3.44 & $9(52.17)$ & 686.90 \\
\hline PEBP1 & P70296 & 21,024 & 7.01 & 3.10 & 5.77 & $3(28.33)$ & 198.37 \\
\hline TUBB4B & P68372 & 50,255 & 4.79 & 2.27 & 2.14 & $15(63.82)$ & 2370.87 \\
\hline ALDOA & P05064 & 37,817 & 8.30 & 3.75 & 4.33 & $8(43.20)$ & 497.32 \\
\hline CALR & P14211 & 48,159 & 4.29 & 1.76 & 3.41 & $11(28.92)$ & 864.52 \\
\hline HSPA5 & P20029 & 72,606 & 5.07 & 1.99 & 4.19 & $21(31.76)$ & 1701.29 \\
\hline PRDX5 & P99029 & 20,423 & 6.00 & 1.91 & 4.29 & $5(17.60)$ & 313.59 \\
\hline HEXB & P20060 & 54,911 & 6.29 & 1.96 & 4.07 & $5(12.82)$ & 319.44 \\
\hline PGK1 & P09411 & 27,881 & 8.30 & 1.33 & 2.77 & $4(11.37)$ & 381.29 \\
\hline PRKAR2A & P12367 & 45,817 & 4.96 & 1.52 & 3.41 & $3(7.37)$ & 167.54 \\
\hline PDIA3 & P27773 & 57,052 & 5.98 & 1.94 & 5.29 & $12(26.14)$ & 770.66 \\
\hline GAPDH & P16858 & 35,936 & 8.57 & 1.51 & 2.86 & $8(31.23)$ & 594.17 \\
\hline GAPDHS * & Q64467 & 35,936 & 8.39 & 1.51 & 2.86 & $8(9.36)$ & 178.10 \\
\hline PRDX1 & P35700 & 22,309 & 8.27 & 2.21 & 4.55 & $4(31.30)$ & 344.45 \\
\hline PRDX2 & Q61171 & 22,163 & 5.66 & 1.50 & 2.93 & $3(15)$ & 230.67 \\
\hline PRDX6 & O08709 & 23,741 & 6.00 & 2.75 & 5.31 & $2(8.93)$ & 96.41 \\
\hline AKR1B3 & P45376 & 36,056 & 6.52 & 2.09 & 3.59 & $2(9.05)$ & 97.03 \\
\hline AKAP3 * & O88987 & 94,787 & 5.84 & 3.52 & 12.72 & $3(3.20)$ & 169.17 \\
\hline YWHAZ & P63101 & 27,898 & 4.73 & 1.27 & 2.65 & $7(30.20)$ & 503.69 \\
\hline ENO1 & P17182 & 47,602 & 7.01 & 1.86 & 2.40 & $9(23.04)$ & 511.79 \\
\hline ССТ3 & P80318 & 61,265 & 6.10 & 5.86 & 89.02 & $2(3.49)$ & 79.20 \\
\hline HSPD1 (HSP60) & P63038 & 55,970 & 5.70 & 1.79 & 6.83 & $7(19.01)$ & 397.55 \\
\hline $\mathrm{ZPBP} *$ & Q62522 & 42,640 & 9.43 & 2.83 & 6.57 & $7(15.26)$ & 386.51 \\
\hline $\mathrm{ZPBP2} \mathrm{*}$ & Q6X786 & 42,640 & 8.04 & 2.83 & 6.57 & $7(22.92)$ & 580.50 \\
\hline HSP90B1 & P08113 & 92,865 & 4.76 & 1.20 & 2.09 & $16(31.49)$ & 1123.06 \\
\hline
\end{tabular}


Table 2. Cont.

\begin{tabular}{|c|c|c|c|c|c|c|c|}
\hline Protein Name & $\begin{array}{c}\text { UniProtKB } \\
\text { IDs }\end{array}$ & MW (Da) & Th.Ip & mFc Male & mFc Female & $\begin{array}{c}\text { No. of } \\
\text { Peptides (\% } \\
\text { Coverage) }\end{array}$ & $\begin{array}{c}\text { Mascot } \\
\text { Score }\end{array}$ \\
\hline PPIA & P17742 & 18,089 & 7.68 & 3.05 & 7.45 & $2(17.83)$ & 206.22 \\
\hline PDIA4 & P08003 & 72,914 & 4.96 & 4.75 & 4.94 & $4(7.01)$ & 217.37 \\
\hline RAB2A & P53994 & 23,545 & 6.08 & 0.27 & 0.32 & $3(15.10)$ & 152.70 \\
\hline
\end{tabular}

The UniProtKb ID, molecular weight (MW), and theoretical isoelectrical point (Th.Ip) are indicated for each protein. The number of peptides and the percentage of coverage, as well as the mascot score, are also indicated. For the mascot score, only the peptides for which the score was greater than or equal to that of a validation with less than $1 \%$ false positive (FDR 1\%) were retained. The mean fold change $(\mathrm{mFC})$ obtained from male and female samples is reported. The stars $\left(^{*}\right)$ indicate proteins strictly expressed in spermatozoa.

Table 3. Proteins recognized by ASA belonging to additional categories.

\begin{tabular}{|c|c|c|c|c|c|c|c|}
\hline Protein Name & $\begin{array}{l}\text { UniProtKB } \\
\text { IDs }\end{array}$ & MW (Da) & Th.Ip & mFc Male & mFc Female & $\begin{array}{c}\text { No. of } \\
\text { Peptides (\% } \\
\text { Coverage) }\end{array}$ & $\begin{array}{c}\text { Mascot } \\
\text { Score }\end{array}$ \\
\hline \multicolumn{8}{|c|}{ DNA/RNA binding } \\
\hline NUP155 & Q99P88 & 156,682 & 5.78 & 7.96 & 3.18 & $5(3.80)$ & 297.33 \\
\hline PPIB & P24369 & 23,754 & 9.42 & 1.84 & 5.53 & $3(15.74)$ & 212.97 \\
\hline SERPINA3 & Q91WP6 & 46,647 & 5.37 & 1.64 & 2.34 & $3(11.87)$ & 103.57 \\
\hline histone H3.1 & P68433 & 15,509 & 10.31 & 2.93 & 3.98 & $5(22.06)$ & 285.16 \\
\hline EEF1A1 & P10126 & 50,440 & 9.10 & 0.79 & 1.30 & $5(10.82)$ & 311 \\
\hline Histone H4 & P62806 & 11,360 & 11.36 & 0.89 & 7.30 & $5(55.34)$ & 396.84 \\
\hline HIST1H1E & $\mathrm{P} 43274$ & 21,882 & 11.03 & 3.75 & 1.15 & $5(23.30)$ & 484.74 \\
\hline TXN1 & P10639 & 11,952 & 9.59 & 1.26 & 2.07 & $2(20.95)$ & 122.51 \\
\hline PPIA & P17742 & 18,089 & 7.68 & 3.05 & 7.45 & $2(17.83)$ & 206.22 \\
\hline Hist1h2bc & Q6ZWY9 & 13,898 & 9.68 & 1.67 & 2.60 & $5(28.57)$ & 319.82 \\
\hline GRHL3 & Q5FWH3 & 67,554 & 6.40 & 1.30 & 0.97 & $2(2.66)$ & 88.29 \\
\hline \multicolumn{8}{|c|}{ Complement activation } \\
\hline $\mathrm{C} 3$ & P01027 & 173,622 & 6.02 & 1.37 & 2.56 & $26(48.50)$ & 7024.70 \\
\hline C1QC & Q02105 & 27,193 & 8.61 & 1.39 & 0.85 & $22(29.10)$ & 1752.80 \\
\hline C1QB & P14106 & 27,193 & 8.83 & 1.73 & 0.99 & $54(40.60)$ & 4681.20 \\
\hline $\mathrm{C} 4 \mathrm{BP}$ & P08607 & 53,951 & 6.83 & 0.85 & 1.05 & $7(14.50)$ & 614.73 \\
\hline CPN2 & Q9DBB9 & 61,608 & 5.63 & 0.95 & 3.61 & $3(4.94)$ & 191.85 \\
\hline $\mathrm{C} 2$ & P21180 & 144,278 & 7.23 & 32.07 & 4.11 & $20(13.10)$ & 1593.08 \\
\hline C1QA & P98086 & 26,093 & 9.26 & 1.35 & 0.87 & $17(29.80)$ & 1017.74 \\
\hline CFI & Q61129 & 69,853 & 7.72 & 1.47 & 2.11 & $8(12.67)$ & 551.94 \\
\hline \multicolumn{8}{|c|}{ Cytoskeletal protein } \\
\hline ACTB & P60710 & 41,890 & 5.29 & 1.30 & 2.41 & $6(14.29)$ & 322.06 \\
\hline TUBA1C & P68373 & 50,566 & 4.96 & 1.34 & 2.49 & $2(36.53)$ & 1498.38 \\
\hline TUBB4B & P68372 & 50,255 & 4.79 & 2.27 & 2.14 & $15(63.82)$ & 2370.87 \\
\hline DSP & E9Q557 & 334,465 & 6.44 & 2.25 & 0.08 & $4(1.25)$ & 169.10 \\
\hline GFAP & P03995 & 49,987 & 5.42 & 0.70 & 0.26 & $1(2.56)$ & 33.58 \\
\hline JUP & Q02257 & 82,479 & 5.75 & 1.34 & 0.31 & $3(4.56)$ & 117.12 \\
\hline MSN & P26041 & 67,816 & 6.08 & 0.59 & 0.62 & $2(2.77)$ & 106.67 \\
\hline \multicolumn{8}{|c|}{ Lipid metabolism } \\
\hline CES1 & Q8VCC2 & 62,577 & 6.15 & 3.75 & 6.59 & $3(8.85)$ & 278.86 \\
\hline CRAT & P47934 & 71,289 & 8.63 & 3.52 & 8.07 & $10(16.45)$ & 605.83 \\
\hline PTGDS & O09114 & 21,523 & 7.66 & 2.23 & 6.21 & $2(8.90)$ & 124.98 \\
\hline NPC2 & Q9Z0J0 & 17,000 & 7.57 & 1.77 & 4.37 & $4(14.67)$ & 198.99 \\
\hline EPHX1 & Q9D379 & 52,808 & 6.77 & 4.86 & Infinity & $2(3.74)$ & 60.14 \\
\hline GK & Q8C635 & 58,210 & 6.12 & 0.83 & 2.96 & $2(4.39)$ & 135.99 \\
\hline GK2 * & Q9WU65 & 58,210 & 5.57 & 0.83 & 2.96 & $2(4.11)$ & 127.32 \\
\hline GK3 * (in human) & Q14409 & 58,210 & 6.00 & 0.83 & 2.96 & $2(4.17)$ & 129.18 \\
\hline APOE & P08226 & 35,619 & 5.65 & 1.08 & 2.31 & $19(44.20)$ & 1278.93 \\
\hline APOA4 & P06728 & 44,043 & 5.28 & 1.03 & 2.23 & $31(48.90)$ & 2557.95 \\
\hline APOM & Q9Z1R3 & 21,771 & 5.66 & 4.92 & 1.79 & $2(8.95)$ & 109.44 \\
\hline APOC1 & P34928 & 9893 & 8.01 & 1.07 & 6.05 & $2(20.45)$ & 104.77 \\
\hline
\end{tabular}


Table 3. Cont.

\begin{tabular}{|c|c|c|c|c|c|c|c|}
\hline Protein Name & $\begin{array}{l}\text { UniProtKB } \\
\text { IDs }\end{array}$ & MW (Da) & Th.Ip & mFc Male & mFc Female & $\begin{array}{c}\text { No. of } \\
\text { Peptides (\% } \\
\text { Coverage) }\end{array}$ & $\begin{array}{c}\text { Mascot } \\
\text { Score }\end{array}$ \\
\hline PON1 & P52430 & 39,785 & 5.08 & 0.46 & 0.58 & $6(23.94)$ & 458.68 \\
\hline ADIPOQ & Q60994 & 26,435 & 5.42 & 0.48 & 1.01 & $2(11.11)$ & 149.13 \\
\hline ECI1 & P42125 & 32,546 & $\begin{array}{c}8.80 \\
\text { Others }\end{array}$ & 2.68 & 1.44 & $2(10.38)$ & 149.01 \\
\hline RPS27A & P62983 & 12,358 & 9.34 & 1.73 & 3.20 & $9(40.19)$ & 503.74 \\
\hline ITIH1 & Q61702 & 101,362 & 6.31 & 1.25 & 3.41 & $11(17.5)$ & 1101.71 \\
\hline AMBP & Q07456 & 39,481 & 5.95 & 1.85 & 4.09 & $2(7.22)$ & 153.34 \\
\hline TTR & P07309 & 15,833 & 11.13 & 1.27 & 2.33 & $15(59.90)$ & 1558.55 \\
\hline ERP44 & Q9D1Q6 & 47,274 & 5.09 & 3.75 & 4.41 & $2(4.93)$ & 61.93 \\
\hline CPN2 & Q9DBB9 & 49,092 & 7.61 & 1.05 & 3.61 & $2(6.87)$ & 105.60 \\
\hline PROC & P33587 & 52,746 & 5.85 & 1.84 & 3.37 & $2(4.16)$ & 84.11 \\
\hline TRF & Q921I1 & 78,371 & 6.81 & 1.09 & 2.13 & $94(52.9)$ & 9020.85 \\
\hline KNG1 & O08677 & 38,818 & 6.34 & 0.84 & 1.53 & $3(21.10)$ & 872.77 \\
\hline ATRN & Q9WU60 & 162,969 & 7.24 & 0.76 & 2.91 & $2(1.20)$ & 80.25 \\
\hline ITIH3 & Q61704 & 78,169 & 5.49 & 0.62 & 1.07 & $2(13.50)$ & 896.4 \\
\hline NMES1 & Q810Q5 & 9589 & 9.45 & 0.72 & 1.12 & $2(11)$ & 71.69 \\
\hline CTSD & $\mathrm{P} 18242$ & 44,768 & 6.10 & 1.63 & 0.75 & $7(14.2)$ & 324.5 \\
\hline SERPINA1 & P07758 & 58,642 & 5.37 & 7.14 & 6.26 & $3(30)$ & 103.57 \\
\hline GSTA3 & P30115 & 22,658 & 9.21 & 9.08 & 1.81 & $2(13.30)$ & 148.63 \\
\hline Il4i1 & O09046 & 72,032 & 8.79 & 2.33 & 4.16 & $5(9.30)$ & 236.71 \\
\hline SERPINA3F & Q80X76 & 45,927 & 4.91 & 1.37 & 1.83 & $8(13.93)$ & 882.80 \\
\hline PZP & Q61838 & 165,815 & 5.97 & 0.86 & 1.17 & $50(21.78)$ & 3570.34 \\
\hline PDIA4 & P08003 & 72,914 & 4.96 & 4.75 & 4.94 & $4(7.01)$ & 217.37 \\
\hline RAB2A & P53994 & 23,545 & 6.08 & 0.27 & 0.32 & $3(15.10)$ & 152.70 \\
\hline CPB2 & Q9JHH6 & 49,092 & 6.72 & 0.34 & 0.35 & $2(3.55)$ & 83.62 \\
\hline
\end{tabular}

The UniProtKb ID, molecular weight (MW), and theoretical isoelectrical point (Th.Ip) are indicated for each protein. The number of peptides and the percentage of coverage, as well as the mascot score, are also indicated. For the mascot score, only the peptides for which the score was greater than or equal to that of a validation with less than $1 \%$ false positive (FDR $<1 \%$ ) were retained. The max fold change $(\mathrm{mFC})$ obtained from male and female samples is reported. The stars $\left(^{*}\right)$ indicate proteins strictly expressed in spermatozoa.

We then arbitrarily set a threshold for the mean fold change at 2 (mFC, corresponding to the quantitative difference for a given protein after its immunoprecipitation with the pre-immune and the immune sera). Among the 120 proteins, 38 had a $\mathrm{mFC}>2$ after IP with both the male and female immune sera (Table S2, not highlighted), 49 were specific to the female sera (Table S2, highlighted in brown), and only four proteins were specific to the male immune sera (Table S2, highlighted in orange). Twenty-nine proteins showed a $\mathrm{mFC}<2$ for both male and female sera (Table S2, highlighted in red). Figure 4 presents the locations of some of the 38 antigens identified with both male and female sera, or spermspecific proteins, with respect to their cell parts and their known functions as deduced from the literature. This figure illustrates that proteins from all cell parts of the ATS spermatozoa triggered an elevated immune response in males and females, in accordance with the IF results presented in Figure 3. Representative of the stronger immune response towards spermatic antigens in female ATS, as proposed in the analysis of Figure 1B,D, is the observation that the mean $\mathrm{mFC}$ was 8.33 with the female immune sera while it was only 2.51 with the male immune sera. The range of molecular weights and isoelectric points of the identified proteins were in agreement with the two-dimensional electrophoresis analysis in Figure 2B,D. Among the 120 identified proteins, 15 were restricted to the sperm cell lineage (identified by an asterisk in Table S2). 


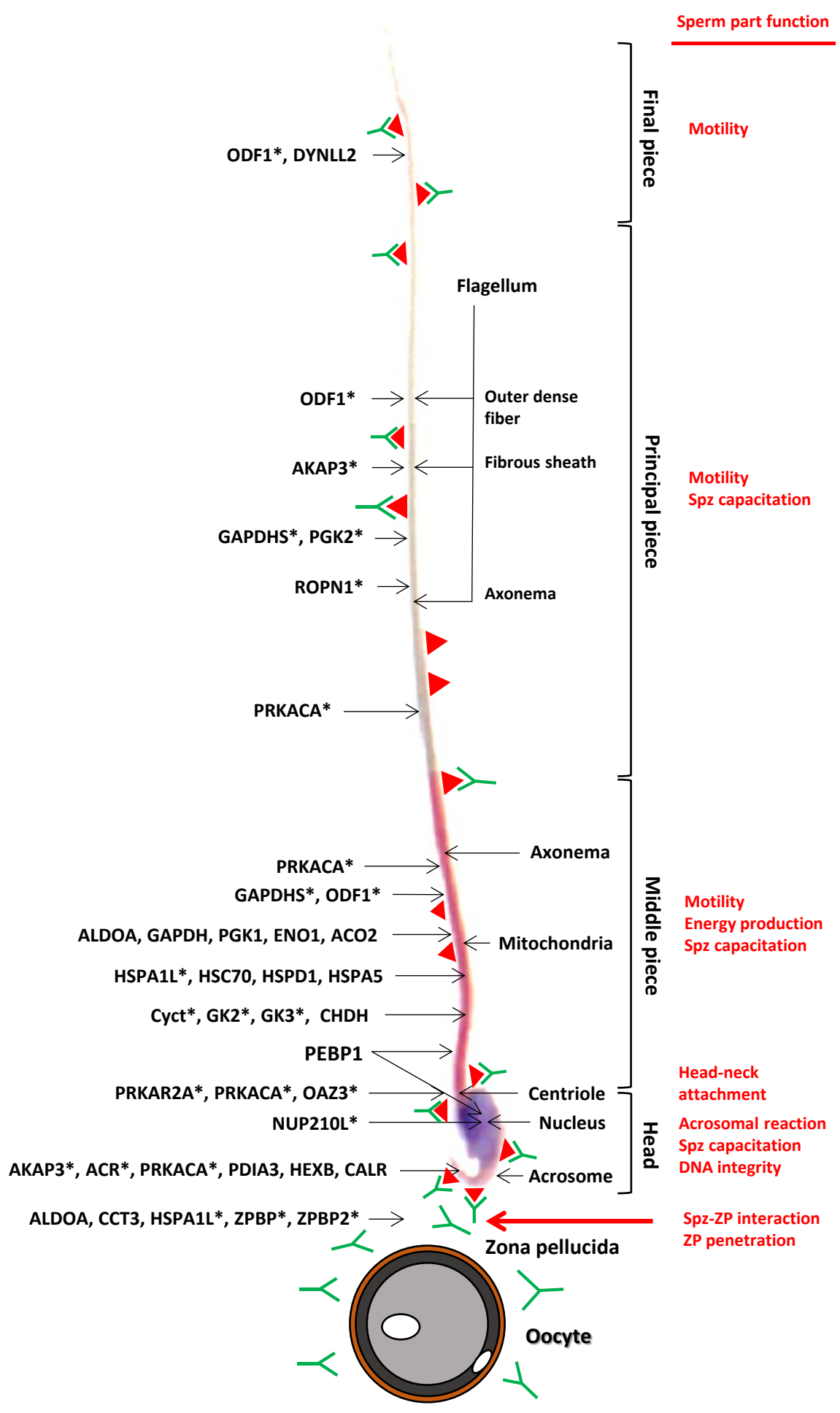

Figure 4. Schematic summary representation of the location of sperm antigens targeted by ASA. Male and female ATS immunized with whole spermatozoa of the same species (ATS) produced serum ASA (immunoglobulin G- and M-isotypes). This figure represents the interaction between an ATS sperm and an oocyte. Some of the antigens identified by LC-MS/MS are represented on the spermatozoon. The red triangles represent proteins targeted by ASA and the green " $Y^{\prime \prime}$ represent ASA. The stars ${ }^{*}$ ) indicate proteins strictly expressed in the spermatozoa (see Tables 1 and 2 for more precise protein classification). The sperm parts and functions concerned by the ASA are mentioned on the right part of the figure. 
As we performed four replicates of the LC-MS/MS analysis, we statistically analyzed the 120 identified proteins in a more stringent manner using a $p$-value $<0.05$ for the mFC (modelled after a statistical test from Mann and Whitney). It turned out that only $22 / 120$ proteins had a statistically significant fold change (Table S2): six with only the male sera (CHDH, PDIA4, GPI1, TUBB4B, C1QB and RAB2A), 14 with only the female sera (EPHX1, DIABLO, CCT3, HSPA1L, AKAP3, CRAT, ROPN1, HSPD1, PEBP1, GAPDH, GAPDHS, PGK1, PGK2 and DSP), and two with both sera (NUP210L and CAR1). Among those, RAB2A and DSP were significantly detected in lower amounts after immunization, so they did not present any interest for the purpose of this study. It is important to point out that 13 proteins had a $p$-value of 0.057 and were increased after immunization, thus making them potentially interesting.

The 22 proteins showing a significant difference were then analyzed using the STRING (https:/ / string-db.org (accessed on 7 July 2020)) database with Mus musculus as a reference as no closer species was available. The GO analysis for "cellular components" presented in Table 4 showed that the three first categories, when classified by the "strength" parameter, were "sperm fibrous sheath", "zona pellucida receptor complex", and "sperm principal piece".

Table 4. Gene ontology (GO) analysis of the 22 proteins showing a significant difference between immune and pre-immune sera. The analysis was carried out using the STRING database (https://string-db.org (accessed on 7 July 2020)). The focus was placed on "cellular components" and the results have been classified using the "strength" parameter in a descending order.

\begin{tabular}{|c|c|c|c|c|c|c|}
\hline \multicolumn{7}{|c|}{ Cellular Components } \\
\hline \# Term ID & $\begin{array}{c}\text { Term } \\
\text { Description }\end{array}$ & $\begin{array}{l}\text { Observed } \\
\text { Gene Count }\end{array}$ & $\begin{array}{l}\text { Background } \\
\text { Gene Count }\end{array}$ & Strength & $\begin{array}{l}\text { False Discovery } \\
\text { Rate }\end{array}$ & $\begin{array}{l}\text { Matching Proteins in } \\
\text { Your Network } \\
\text { (Labels) }\end{array}$ \\
\hline GO:0035686 & $\begin{array}{l}\text { Sperm fibrous } \\
\text { sheath }\end{array}$ & 2 & 12 & 2.31 & 0.0037 & GAPDHS, AKAP3 \\
\hline GO:0002199 & $\begin{array}{l}\text { Zona pellucida } \\
\text { receptor complex }\end{array}$ & 2 & 13 & 2.28 & 0.0037 & CCT3, HSPA1L \\
\hline GO:0097228 & $\begin{array}{l}\text { Sperm principal } \\
\text { piece }\end{array}$ & 2 & 29 & 1.93 & 0.0094 & GAPDHS, AKAP3 \\
\hline GO:0043209 & Myelin sheath & 6 & 212 & 1.54 & $1.91 \mathrm{e}-06$ & $\begin{array}{l}\text { CCT3, HSPD1, } \\
\text { TUBB4B, PEBP1, } \\
\text { GPI1, GAPDH }\end{array}$ \\
\hline GO:0005740 & $\begin{array}{l}\text { Mitochondrial } \\
\text { envelope }\end{array}$ & 4 & 590 & 0.92 & 0.0283 & $\begin{array}{l}\text { HSPD1, CRAT, } \\
\text { PEBP1, DIABLO }\end{array}$ \\
\hline GO:0031967 & $\begin{array}{l}\text { Organelle } \\
\text { envelope }\end{array}$ & 5 & 1015 & 0.78 & 0.0283 & $\begin{array}{l}\text { HSPD1, CRAT, PEBP1, } \\
\text { DIABLO, GAPDH }\end{array}$ \\
\hline
\end{tabular}

Altogether, these results demonstrated that an efficient immune response was triggered by immunization of ATS with whole spermatozoa, that the different immunogenic proteins are located all along the sperm cell, and some of them are strictly sperm-specific (GAPDHS, HSPA1L, and AKAP3).

\subsection{Immunization of Male ATS with Peptides from Two Candidate Proteins}

The presence of serum IgG specifically directed against the injected peptides was clearly visible using slot blot detection (Figure 5A). The intensity of the immune response was higher for $\mathrm{CHDH}$ compared to ZPBP2, as shown by the high signal intensities obtained for $\mathrm{CHDH}$, even with the lowest amount of peptide deposited. This is in accordance with the results obtained with the proteomic analysis (see Table S2). After immunization with the $\mathrm{CHDH}$ peptide, the immune sera detected a protein present on the acrosome and in the midpiece (Figure 5B, left panel). CHDH is a mitochondrial protein, the staining of the midpiece was thus expected. More surprisingly, an intense staining was also revealed on the acrosome with the immune sera, a point that will be discussed. Immunization against 
ZPBP2 triggered the production of IgG binding to a protein mainly present on the acrosome (Figure 5B, right panel), in accordance with what was expected.

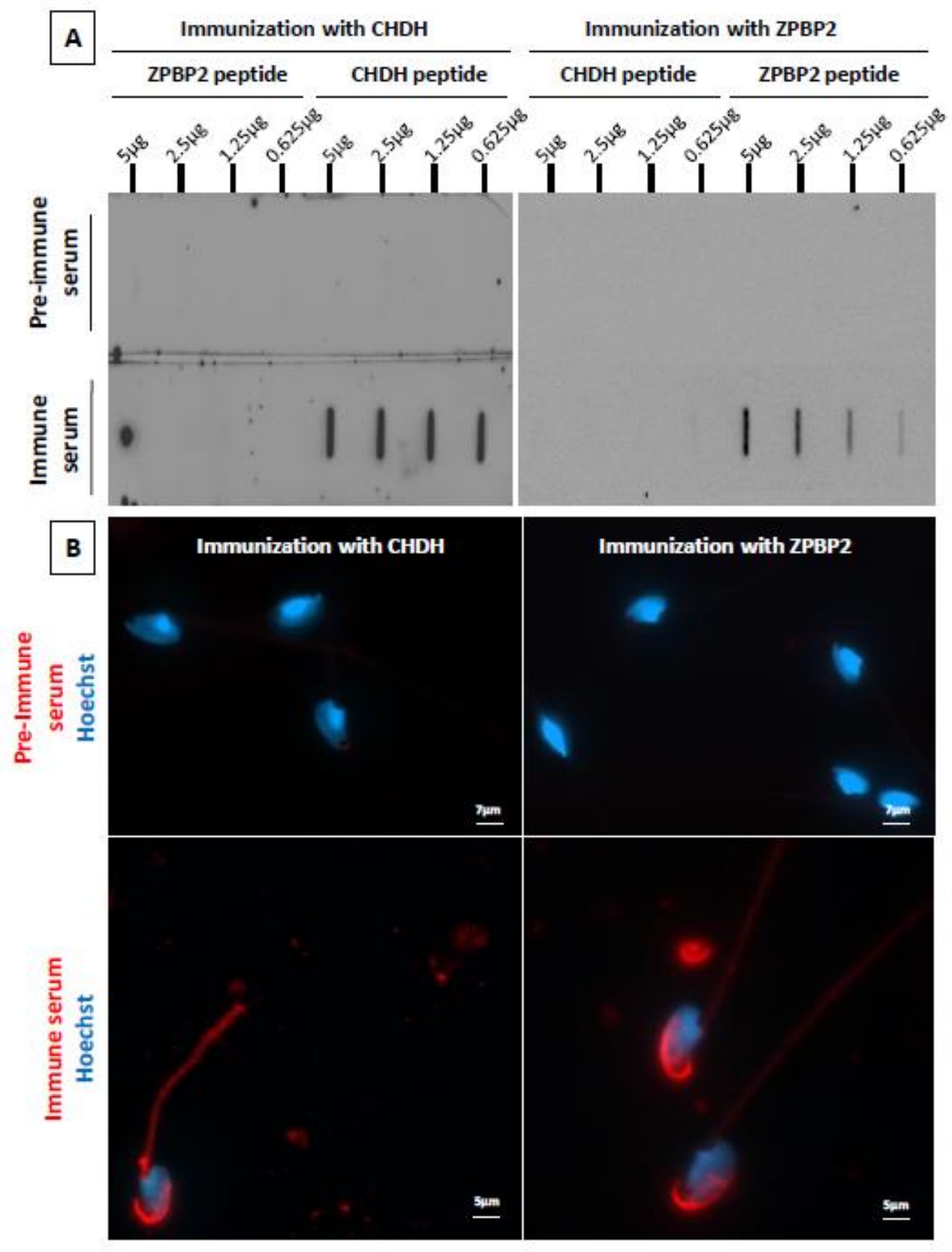

Figure 5. Immune response of male ATS immunized with species-specific peptides. Male ATS were immunized with a peptide of the $\mathrm{CHDH}$ or the ZPBP2 protein. (A) The presence of IgG in the pre-immune and immune sera was detected by a slot blot against decreasing quantities of the injected peptide. The specificity of the response was evaluated by blotting each serum against the two peptides. (B) Fresh ATS spermatozoa were double labelled with male ATS pre-immune or immune sera (red) and Hoechst 33342 (blue) and observed using an epifluorescence microscope (Zeiss) equipped with a digital camera, and the micrographs were taken using Zen software (Zeiss). The results in $(\mathbf{A}, \mathbf{B})$ are representative of experiments obtained with three different immunized male ATS for each peptide.

These two immunization experiments with ATS-specific peptides for CHDH and ZPBP2 confirm the high potential of the identified proteins for the development of an immunocontraceptive vaccine. 


\section{Discussion}

The objective of this study was to identify antigenic and immunogenic targets on ATS spermatozoa that could form the basis of a contraceptive vaccine. To this end, male and female ATS were immunized with whole spermatozoa and their sera were evaluated for the presence of anti-sperm antibodies. The sera were then used to identify the sperm antigens that triggered the immune responses using a combination of 2D gel electrophoresis, immunocytochemistry, immunoprecipitation, and LC-MS/MS mass spectrometry. To our knowledge, to date, five studies reporting immunizations using whole sperm have been performed in different animal models, such as tammar wallabies [31], mice [32,40,41], opossum brushtails [18], and dogs [35]. In these studies, only qualitative analyses of triggered immune responses and consequences on fertility were reported. No identification of the antigens targeted by the generated ASA was performed. This study revealed that 120 different sperm proteins had the capacity to trigger an immune reaction in ATS under our experimental conditions. Our strategy allowed the identification of the totality of these proteins, thus providing a very interesting source of putative antigens to use in a future contraceptive vaccine.

Not surprisingly, ATS females showed a higher immune response to sperm antigens than ATS males, as confirmed by the higher number of proteins showing a significant difference after IP and LC-MS/MS analysis (14 vs. 6 for the males, with two proteins for both sexes). The overall $\mathrm{mFC}$ for proteins identified with female sera was also higher than for male sera ( 8.33 vs. 2.51 , respectively). This was expected as spermatic antigens are definitely foreign to the female immune library, while for the male, a tolerogenic status is established with respect to some spermatic antigens to avoid self-reactivity [42]. This may partly explain why male ATS do not react strongly to all autoantigens. In addition, it is well documented that there are sex-related differences in the ability to respond to vaccinations. In humans, women have been found to produce more antibodies and have higher B-cell counts than men $[43,44]$. This phenomenon has been more recently associated with the observation that estradiol, at physiological concentrations, stimulates antibody production [40].

In addition to this quantitative aspect, we noted that the immune responses of female ATS were, in part, qualitatively distinct from those of male ATS. Although both male and female animals reacted to sperm antigens located on the sperm head and the acrosomal region, it was clear that part of the immune response of female ATS to spermatozoa was specific to antigens located in the midpiece, mainly of mitochondrial origin. In contrast, male ATS showed no reactivity against sperm antigens located in the midpiece, but showed specific immune responses against antigens located at the flagellum tip (terminal end). Female ATS immunization triggered intense immune responses against antigens from sperm mitochondria, a fact that is not in accordance with the maternal origin of mitochondria inheritance. A possible cause would be that proteins of the male germline mitochondria are antigenically distinct or present at different levels. Such a mitochondrial sexual dimorphism has already been suggested $[45,46]$. Despite the fact that these spermmitochondria-associated antigens triggered relatively good immune responses in female ATS, they are unlikely to be good candidates for a species-specific vaccine. Indeed, these antigens are mainly proteins involved in energy metabolism, a critical function for sperm motility [47], but without any cell and/or species specificity [48]. Apart from the special case of mitochondrial sperm antigens, it is surprising to note that only male ATS built immune responses against antigens located at the flagellum tip, while female ATS did not. Once again, this confirms the idea that there are sex-specific immune responses and, within each sex, inter-individual immune responses that could logically be expected from field trapped animals that are not clonal and, therefore, have different antigen presentation capabilities due to their MHC (major histocompatibility complex) polymorphism. A common feature between males and females was the presence in the pre-immune sera of antibodies recognizing sperm proteins, as visible in Figures 1 and 2. These proteins were probably not specific to the sperm lineage and they triggered immune responses due to 
inter-individual polymorphisms. The intensity of this response was weak, as confirmed by the very faint staining observed when performing an immunofluorescence on spermatozoa with the pre-immune sera, as shown in supplementary Figure S3.

Of the 120 ATS sperm antigens identified in this study, 15 were found to be strictly limited to the sperm lineage, most of which were described as plasma membrane-integrated or extracellular components. Using the power of the four replicates performed in the LCMS/MS analysis, the number of sperm antigens capable of eliciting significant immune responses decreased to 22. The analysis of these 22 proteins using the "STRING" database, and considering the "cell compartments", showed the three major categories were sperm parts (Table 4), thus strengthening the fact that an efficient and sperm-specific immune response was triggered by the subcutaneous injection of whole spermatozoa. When considering a threshold value of 2 for the mean fold change after immunization, a number of 91 proteins elicited a response. This means that some proteins, even though not showing a statistical significance due to the experimental design, may be efficient targets. The case of the protein $\mathrm{CHDH}$ is an illustration of that as the $\mathrm{mFC}$ was 21.01 for the males and 20.78 for the females, but it was statistically significant only for the males (Table S2). This study revealed that a selected peptide of the $\mathrm{CHDH}$ protein is indeed immunogenic when injected subcutaneously in male ATS. Further investigations on other proteins will be needed to determine their potential as a contraceptive target. This work is currently in progress.

Twenty-nine proteins have already been identified in the epididymosomes of cattle [49,50], mice [51], or men [52], as reported in Table 2. Epididymosomes are small apocrine secretory vesicles emanating from the epididymal epithelium [53]. They function as cargo ships between the epididymal epithelium and maturing spermatozoa, transporting mainly proteins, lipids, and small RNAs. Immunizing ATS against some of these proteins (listed in Table 2) could be of interest because it could have two consequences. The first would be to target sperm antigens added to the sperm cells during the post-testicular phases (thus avoiding testis-specific antigens) and the second would be to potentially impede the transfer from the epididymosomes to the spermatozoa. We believe that this is very possible because the epithelium of the caput epididymis is suspected to be highly permeable to the systemic compartment, offering the opportunity to antibodies to reach the epididymal lumen and, consequently, the epididymosomes and spermatozoa [54,55].

Among the identified sperm proteins, YWHAZ or protein 14-3-3 $\zeta$, also known as tyrosine 3-monooxygenase/tryptophan 5-monooxygenase activation protein zeta, a member of the YWHA family of adaptor proteins, particularly caught our attention. It is present in human [52] and mouse epididymosomes (M. Whitfield, personal communication) and it is a major protein for sperm functions, as described in bovine studies [56]. We previously showed that disorders of the mouse sperm capacitation process could be associated with decreased sperm YWHAZ content in a pathological situation such as dyslipidemia [57]. As YWHAZ function is central for male fertility, if the ATS YWHAZ protein contains an ATS-specific epitope with immunogenic potential, it could be considered as a contraceptive antigen worth testing.

The production levels of ASA against some of the identified sperm antigens have already been reported in different species and under different circumstances. In male deer, the production of mucosal sperm-reactive antibodies against ACR, PGK2, and ENO1 was described [58]. Antibodies against ENO1, ALDOA, GAPDH, and ODF1 were also detected in human semen from infertile men [59]. Serum antibodies against GAPDHS were reported in higher concentrations in infertile men and women as compared to fertile individuals [60]. Three of these proteins (ACR, GAPDHS, and ODF1) are strictly present on spermatozoa, making them good sperm-cell-specific antigens. Among the sperm antigens identified, several are known to be involved in key steps of the fertilization process, such as HSPA1L [61], CCT3 [62], ZPBP and ZPBP2 [63], and HSPD1 [64,65]. Others, such as AKAP3 and ROPN1, are associated with the acrosomal reaction process $[66,67]$. These 
sperm antigens, because of their involvement in major fertilization events, also represent good vaccine targets.

Male ATS immunized against two species-specific peptides of the $\mathrm{CHDH}$ (choline dehydrogenase) and the ZPBP2 (zona pellucida-binding protein 2) proteins developed specific immune responses, confirming that these two proteins are interesting targets. The immune sera obtained after $\mathrm{CHDH}$ immunization contained IgG that could bind both the midpiece and the acrosome region of ATS spermatozoa.

In conclusion, the immunization of male and female ATS with whole spermatozoa has allowed the identification of a significant number of potential sperm immunogenic antigens. Sex specificity of immune responses was observed both quantitatively and qualitatively. This paves the way for the development of a multi-antigen vaccination strategy to optimally target male and female partners. Some of the sperm antigens identified here are already known to provoke the generation of anti-sperm antibodies that interfere with reproductive success in various species. Others have been identified here for the first time, further expanding the options for developing a multi-targeted vaccine. The next step towards the generation of this vaccine in ATS will be to select, on these sperm antigens, immunogenic peptidic epitopes with sufficient sequence specificity to limit their immunogenicity to ATS so as to limit possible collateral effects on off-target fauna. Ultimately, one of the challenges will be to find the most effective route of administration of such a vaccine that could provide an alternative to the current chemical strategy used to control ATS outbreaks. Finally, the strategy used in this work represents a proof of concept that can be transposed on other wild harmful or invasive species to identify sperm antigens to be used for contraceptive vaccines with the aim of controlling their proliferation.

\section{Materials and Methods}

\subsection{Animals}

Male and female Arvicola terrestris Scherman (ATS) were collected in open fields in the region of Puy-de-Dôme (France): Perpezat $\left(45^{\circ} 68^{\prime} 33^{\prime \prime} \mathrm{N}-2^{\circ} 78^{\prime} 33^{\prime \prime}\right.$ E); Nébouzat $\left(45^{\circ} 42^{\prime} 59^{\prime \prime} \mathrm{N}-2^{\circ} 54^{\prime} 19^{\prime \prime} \mathrm{E}\right)$; Saint-Julien-Puy-Lavèze $\left(45^{\circ} 39^{\prime} 58^{\prime \prime} \mathrm{N}-2^{\circ} 40^{\prime} 25^{\prime \prime} \mathrm{E}\right)$. In the immediate vicinity of freshly made molehills, galleries were detected with a sounder and a trap was placed inside. Only animals of reproductive age, that is with a weight greater than $70 \mathrm{~g}$, were kept alive and brought back to the animal facility where they were housed in a controlled environment $\left(23^{\circ} \mathrm{C}, 12 \mathrm{~h}\right.$ light $/ 12 \mathrm{~h}$ dark). The ATS were fed ad libitum with carrots. All the following procedures were approved by the Auvergne Animal Experiment Ethics Committee (C2E2A) and the French Ministry for Research (APAFIS authorization \# $10653-2017071016422159 \mathrm{v} 5)$. The animals were anesthetized using $4 \%$ isoflurane (Isovet) in the inhaled air to perform the injections and blood sampling. They were then killed by cervical dislocation before tissue sampling.

\subsection{Production of Horseradish Peroxidase (HRP)—Conjugated Rabbit Anti-ATS Immunoglobulin $G(\operatorname{IgG})$ Antibodies}

To perform Western blot and immunofluorescence analyses, the production of a specific antibody directed against immunoglobulin G (IgG) from ATS was crucial. As mentioned above, blood was retrieved from anesthetized adult males and females ATS by intracardiac puncture and incubated overnight at $4{ }^{\circ} \mathrm{C}$. Blood was centrifuged $(1700 \times g$, $20 \mathrm{~min}, 4^{\circ} \mathrm{C}$ ) to collect the IgG-containing serum. Briefly, ATS IgG samples were purified using protein $\mathrm{A} / \mathrm{G}$ columns. Two rabbits were immunized with these purified IgG. Immunizations were carried out at day 0 (primo-injection) and at day 7 (booster \#1), day 14 (booster \#2), and day 34 (booster \#3). Sera were then collected on day 63 by exsanguination, and rabbit IgG were purified using A-protein columns before being conjugated to horseradish peroxidase (HRP). The biotech company Agrobio (La Ferté-Saint-Aubin, France) produced this secondary antibody. 


\subsection{Animal Immunization Procedure}

Whole ATS spermatozoa $\left(15 \times 10^{7} \mathrm{spz} /\right.$ injection in a total volume of $300 \mu \mathrm{L}$, corresponding to an immunogenic dose based on protein content) were injected subcutaneously between the two shoulder blades of male and female ATS. Before spz injection, a blood fraction was collected in the tail vein to retrieve the pre-immune sera. Five males and six females were simultaneously immunized with whole spz. The immunization procedure lasted 6 weeks: on the first day, spz $\left(15 \times 10^{7}\right)$ were injected with an equal volume of complete Freund's adjuvant (Sigma, Saint-Quentin Fallavier, France) corresponding to primo-injection. After three weeks, the same spz quantity was injected, diluted in an equal volume of incomplete Freund's adjuvant (booster \#1). The immunization procedure was stopped after six weeks and blood was collected by intracardiac puncture under anesthesia, as described above, to retrieve the immune sera. Control immunizations were performed by injecting Freund's adjuvant alone diluted in PBS. Animals were sacrificed by cervical dislocation. The time of vaccination was determined based on a proof-of-concept study [34].

\subsection{Sperm Collection}

For all experiments, spz were collected by pressure on cauda epididymis in $500 \mu \mathrm{L}$ of Whitten's HEPES buffer (WH: $100 \mathrm{mM} \mathrm{NaCl}, 4.7 \mathrm{mM} \mathrm{KCl}, 1.2 \mathrm{mM} \mathrm{KH}_{2} \mathrm{PO}_{4}, 1.2 \mathrm{mM}$ $\mathrm{MgSO}_{4}, 5.5 \mathrm{mM}$ glucose, $1 \mathrm{mM}$ pyruvic acid, $4.8 \mathrm{mM}$ lactic acid, $20 \mathrm{mM}$ HEPES, $\mathrm{pH} 7.4$ ). After $30 \mathrm{~min}$ at $37^{\circ} \mathrm{C}$ to release a maximum of spz from the cauda epididymis, spz were retrieved, an aliquot was diluted (1:50 in WH), and they were counted using a Malassez hemacytometer. They were finally washed three times by centrifugation in PBS $(500 \times g$, $5 \mathrm{~min}$, room temperature- $\mathrm{RT}$ ) and the final pellet was frozen and kept at $-20{ }^{\circ} \mathrm{C}$ until use.

\subsection{Extraction of Sperm Proteins}

For mono-dimensional SDS-PAGE analyses, the spz from cauda epididymides were incubated in RIPA buffer for $2 \mathrm{~h}$ at RT ( $50 \mathrm{mM}$ Tris, $150 \mathrm{mM} \mathrm{NaCl}, 12 \mathrm{mM}$ sodium deoxycholate, $3 \mathrm{mM}$ sodium dodecyl sulfate, $1 \%$ Igepal CA-630) supplemented with protease inhibitors (Complete Mini, Roche Diagnostics, Meylan, France) and phosphatase inhibitors (Halt Phosphatase Inhibitor Cocktail, Thermo Scientific, Waltham, MA, USA). Samples were then sonicated for $30 \mathrm{~min}$ with a $30 \mathrm{~s} / 30 \mathrm{~s}$ cycle at $4{ }^{\circ} \mathrm{C}$ (Bioruptor UCD-200TM-EX, Diagenode, Liege, Belgium). Cell lysates were centrifuged $\left(12,000 \times g, 10 \mathrm{~min}, 4^{\circ} \mathrm{C}\right)$ and the supernatants containing easily solubilized proteins were recovered for the determination of protein concentrations by the Bradford assay (Biorad, Hercules, CA, USA) with bovine serum albumin (BSA, Euromedex, Souffelweyersheim, France) as the standard. Samples were then frozen at $-20^{\circ} \mathrm{C}$ until analyses.

For two-dimensional electrophoresis analyses, spz proteins were extracted using the commercially available ReadyPrep protein extraction kit (BioRad). This kit allows the preparation of total cellular protein extracts using strong chaotropic agents such as the zwitterionic detergent ASB-14. Briefly, spz were resuspended ( $2 \mathrm{~h}, \mathrm{RT})$ in lysis buffer $(7 \mathrm{M}$ urea, $2 \mathrm{M}$ thiourea, $1 \%(w / v)$ ASB-14 detergent, $40 \mathrm{mM}$ Tris base, $0.001 \%$ Bromophenol Blue, $200 \mathrm{mM}$ tributylphosphine, Bio-Lyte 3/10) and supplemented with protease inhibitors and phosphatase inhibitors. Samples were sonicated for $30 \min (30 \mathrm{~s} / 30 \mathrm{~s})$ at $4{ }^{\circ} \mathrm{C}$ and then centrifuged at RT $(16,000 \times g, 20 \mathrm{~min})$ to remove insoluble material. The protein concentration was determined using the bicinchoninic acid assay (Biorad) with BSA as standard.

\subsection{Serum Globulin Profile with Amido Black Staining}

Agarose gel electrophoresis was carried out $(180 \mathrm{~V}, 2 \mathrm{~h})$ on different sera from ATS to compare the immune and pre-immune sera of each animal. Total serum proteins were mixed with alkaline veronal buffer, $\mathrm{pH}$ 8.2 (5,5-Diethylbarbituric acid sodium salt) at the dilution $\frac{1}{4}$ and supplemented with Green GoTaq Flexi Buffer (Promega, Madison, WI, USA). Total serum proteins were separated on $1 \%$ agarose gels (Euromedex) in veronal buffer. The 
different fractions of ATS serum proteins were visualized by direct coloration with amido black 10B (4-Amino-5-hydroxy-3-[(4-nitrophenyl)azo]-6-(phenylazo)-2,7-naphthalene disulfonic acid, Merck, Lyon, France). The gels were fixed for $2 \mathrm{~h}$ with a methanol/glacial acetic acid/distilled water solution (volume ratio $4 / 1 / 4$ ), then stained for $15 \mathrm{~min}$ with the staining solution (amido black: $1.25 \mathrm{~g}$ dissolved in $5 \%$ acetic acid), and, finally, discolored for 2 days in a bleaching solution (acetic acid 5\%).

\subsection{Western Blot Analysis}

Thirty $\mu \mathrm{g}$ of spz proteins were loaded onto $12 \%$ SDS-PAGE gel. After migration, proteins were transferred on PVDF membranes (Hybond ECL, Amersham Biosciences, Sigma) activated in absolute ethanol (10 min, RT). Membranes were blocked ( $1 \mathrm{~h}, \mathrm{RT})$ with Tris-buffered-saline (TBS) $(50 \mathrm{mM}$ Tris, $150 \mathrm{mM} \mathrm{NaCl}$ ) containing $0.1 \% v / v$ Tween-20 (TBS-T) and 5\% $w / v$ BSA. Membranes were hybridized in TBS-T, 2\% $w / v$ BSA with either ATS immune or pre-immune serum (dilution 1:1000, overnight, $4^{\circ} \mathrm{C}$ ) or with rabbit antiGAPDH (1:10,000, Sigma). Membranes were then washed three times with TBS-T (10 min, RT) and further hybridized with HRP-conjugated rabbit anti-ATS IgG antibody (Agrobio) or HRP-conjugated anti-rabbit antibody for GAPDH (BI 2407, dilution 1:5000, Abliance, Compiègne, France) for $1 \mathrm{~h}$ at RT. Membranes were finally washed thrice with TBS-T $(3 \times 10 \mathrm{~min})$. The protein bands were detected with chemiluminescent reagents (Clarity Western ECL Substrate, Biorad) using a ChemiDoc MP Imaging System (Biorad).

\subsection{Two-Dimensional Electrophoresis Analysis}

IsoElectric focusing (IEF) was performed on IPG $11 \mathrm{~cm}$ long (pH 3-10) strips (Biorad) using $200 \mu \mathrm{g}$ of proteins. IEF was carried out using a PROTEAN IEF Cell (Biorad) as follows: passive rehydration $(10 \mathrm{~h})$, active rehydration at $50 \mathrm{~V}(12 \mathrm{~h})$, and migration $(250 \mathrm{~V}$ for $15 \mathrm{~min}, 8000 \mathrm{~V}$ for $2 \mathrm{~h} 30$, and a final phase of $8000 \mathrm{~V}$ up to a maximum of $35,000 \mathrm{~V} / \mathrm{h}$ ). Following IEF, the focused strips were rotated in $135 \mathrm{mM}$ dithiothreitol (Euromedex) in equilibration buffer (6 M urea; $2 \%$ SDS; $0.375 \mathrm{M}$ Tris- $\mathrm{HCl} \mathrm{pH} \mathrm{8.8;} 20 \%$ glycerol, $10 \mathrm{~mL}$ for $15 \mathrm{~min}$ ) and, subsequently, in $135 \mathrm{mM}$ iodoacetamide (Sigma) in equilibration buffer (10 mL for $15 \mathrm{~min}$ ). Second-dimension gels ( $1 \mathrm{~mm}$ thick, $4-15 \%$ gradient acrylamide, Criterion TGX-IPG $11 \mathrm{~cm}+1$ well precast gels, Biorad) were run $(5 \mathrm{~h}, 80 \mathrm{~V})$ using the criterion cell (Biorad). Proteins were then transferred on activated PVDF membranes and blocked with TBS-T, 5\% $w / v$ BSA. Membranes were hybridized with pre-immune or immune serum (1:1000, overnight, $\left.4{ }^{\circ} \mathrm{C}\right)$, anti-beta-actin (1:2500, Sigma), or anti-GAPDH (1:10,000, Sigma) and secondary antibodies were applied after three washing steps in TBS-T: rabbit HRPconjugated anti-ATS IgG antibody (1:1000, $1 \mathrm{~h}$, RT) or HRP-conjugated anti-rabbit IgG antibody (BI 2407, 1:1000 for beta-actin and 1:5000 for GAPDH, Abliance). Protein spots were finally revealed by ECL as described above.

\subsection{Direct Immunofluorescent Labelling of Sperm Cells}

Before experiments, slides (Superfrost, Thermo Scientific) were treated with acetone (45 min, RT) and stored in absolute ethanol $\left(-20^{\circ} \mathrm{C}\right)$ until use. The cauda epididymis of non-immunized ATS were perforated with a needle in WH buffer and incubated for $30 \mathrm{~min}$ at RT. Spz were recovered by centrifugation $(500 \times g, 5 \mathrm{~min})$, washed thrice with PBS, smeared onto slides, and allowed to air dry $(1 \mathrm{~h}, \mathrm{RT})$. Slides were then washed twice for $5 \mathrm{~min}$ in PBS without shaking. Saturation was performed with PBS containing $0.1 \% w / v$ BSA $(1 \mathrm{~h}, \mathrm{RT})$ and the slides were incubated with pre-immune or immune serum $(1: 1000$, overnight, $4{ }^{\circ} \mathrm{C}$ ) in a solution of PBS, $0.01 \%$ Tween-20 (PBS-T) containing $0.1 \% w / v$ BSA. As fluorescent secondary antibodies directed against ATS IgG are not available, slides were incubated with a rabbit anti-IgG ATS antibody (1:1000, Agrobio) in PBS, 0.1\% BSA (1 h, RT) before applying an Alexa Fluor 555-conjugated goat anti-rabbit IgG antibody (1:1000, $1 \mathrm{~h}, \mathrm{RT}$, Invitrogen, Thermo Scientific). After two washes, slides were incubated in PBS-T, $0.1 \%$ w/v BSA either with lectin-PNA from Alexa Fluor 488-conjugated Arachis hypogaea agglutinin (1:20, $30 \mathrm{~min}, 37^{\circ} \mathrm{C}$, Invitrogen) or with MitoTracker Green FM Dye (1:5000, 
$30 \mathrm{~min}, 37^{\circ} \mathrm{C}$, Invitrogen). After two washes with PBS, nuclei were stained with Hoechst $33342(1 \mu \mathrm{g} / \mathrm{mL}$ in PBS, $5 \mathrm{~min}$ in the dark, Invitrogen). Slides were finally mounted in a Citifluor AF100 anti-fading solution and Citifluor Tris-MWL 4-88 (ratio 1:9 respectively, Electron Microscopy Sciences, Hatfield, PA, USA) and stored at $+4{ }^{\circ} \mathrm{C}$ until observation by confocal microscopy.

\subsection{Confocal Microscopy}

The acquisition of triple staining was done using a Leica SP8 laser scanning confocal microscope, equipped with a Plan Apo $\lambda$ 40X Oil objective, with a pinhole size of 1 AU (arbitrary unit), Z-step: $0.15 \mu \mathrm{m}$. The parameters used for the channels series with lectinPNA Alexa Fluor 488 conjugate were as follows: Channel 1 (Laser 405 nm): Hoechst 33342 detection window between $430 \mathrm{~nm}$ and $531 \mathrm{~nm}$ using a Hybrid detector at a gain of 10\%. Channel 2 (laser 488 nm): lectin-PNA Alexa Fluor 488: detection window 493 nm-541 nm, using a Hybrid detector at a gain of 10\% gain. Channel 3 (laser $552 \mathrm{~nm}$ ): Alexa Fluor 555 detection window $569 \mathrm{~nm}-621 \mathrm{~nm}$ using a PMT detector at a gain of $700 \mathrm{~V}$.

The parameters used for the channels series with MitoTracker Green FM Dye were as follows: Channel 1 (Laser $405 \mathrm{~nm}$ ): Hoechst 33342 detection window between $430 \mathrm{~nm}$ and $531 \mathrm{~nm}$ using a Hybrid detector at a gain of 15\%. Channel 2 (laser $488 \mathrm{~nm}$ ): PNA Alexa Fluor 488: detection window $493 \mathrm{~nm}$ and $541 \mathrm{~nm}$, using a Hybrid detector at a gain of 10\%. Channel 3 (laser $552 \mathrm{~nm}$ ): Alexa Fluor 555: detection window between $569 \mathrm{~nm}$ and $621 \mathrm{~nm}$ using a PMT detector at a gain of $700 \mathrm{~V}$. Z-stack images were taken through representative spz to enable projected image reconstruction using an image analysis software Imaris 7.6 (Bitplane AG, Scientific Software, Zurich, Switzerland). Images were reconstructed in 3D form using isosurface rendering to determine the nature of the relationship between immunolabeling markers. These images' acquisitions were carried out at the Confocal Microscopy Facility CLIC (Clermont Imagerie Confocale) at Université Clermont Auvergne, iGReD Laboratory (France).

\subsection{Indirect Immunoprecipitation Assays}

Spz from cauda epididymis were collected as described earlier, and $10 \times 10^{7} \mathrm{spz}$ cells were incubated in $1.2 \mathrm{~mL}$ RIPA buffer with protease and phosphatase inhibitors ( $2 \mathrm{~h}, \mathrm{RT})$. After sonication as described earlier, lysates were centrifuged $\left(12,000 \times g, 10 \mathrm{~min}, 4{ }^{\circ} \mathrm{C}\right)$. One hundred $\mu \mathrm{L}$ samples of supernatants were incubated with protein $\mathrm{A} / \mathrm{G}$ magnetic beads (30 min, $4{ }^{\circ} \mathrm{C}$, Dynabeads Protein G, Thermo Scientific) for pre-clearing. Then, this pre-clearing supernatant was incubated with $25 \mu \mathrm{L}$ of either immune serum or pre-immune serum with slight rotation $(7 \mathrm{rpm})$ overnight at $4{ }^{\circ} \mathrm{C}$ (to limit proteolysis). Supernatants (now containing antibodies-antigen complexes) were incubated with protein A/G magnetic beads ( $4.5 \mathrm{mg} / \mathrm{mL}$, Thermo Scientific) with slight rotation $(2 \mathrm{~h}, \mathrm{RT})$. The beads-antibodiesantigen complexes were eluted with $35 \mu \mathrm{L}$ of elution buffer (50 mM glycine, $\mathrm{pH} 2.8$ ) for $20 \mathrm{~min}$ at RT in order to detach the beads from the Ab-Ag complexes. On one hand, protein A/G magnetic beads $(4.5 \mathrm{mg} / \mathrm{mL})$ were again added to separate antibodies and antigens. The antigen-containing supernatants were mixed with Laemmli $4 \times$ buffer and boiled at $95{ }^{\circ} \mathrm{C}$ for $10 \mathrm{~min}$. On the other hand, magnetic beads were washed thrice with $200 \mu \mathrm{L}$ of PBS and boiled at $95^{\circ} \mathrm{C}$ for $10 \mathrm{~min}$ in $25 \mu \mathrm{L}$ of Laemmli $4 \times$ buffer before SDS-PAGE Western blot as described above.

\subsection{In-Gel Trypsin Digestion}

Proteins obtained by immunoprecipitation (above) were migrated in a stacking polyacrylamide gel $(12 \%)$ and the 1D bands (protein gel) of interest excised from the G250 Blue (Thermo Scientific)-stained SDS-PAGE gel (approximately $5 \mathrm{~mm}$ length fragments) were reduced with $200 \mu \mathrm{L}$ of $10 \mathrm{mM}$ Dithiothreitol (Euromedex) in $50 \mathrm{mM}$ ammonium bicarbonate buffer (Sigma) at $56^{\circ} \mathrm{C}$ for $1 \mathrm{~h}$. Then, it was followed by the alkylation with $55 \mathrm{mM}$ iodoacetamide (Sigma) in the same buffer at RT for $30 \mathrm{~min}$ in the dark. Then, the protein gels were discolored with $100 \mu \mathrm{L}$ of $5 \%(15 \mathrm{~min})$ and 50\% (30 min) acetonitrile 
successively in $25 \mathrm{mM}$ ammonium bicarbonate buffer. They were then dehydrated by incubation in $200 \mu \mathrm{L}$ of $100 \%$ acetonitrile for $10 \mathrm{~min}$. The protein gel was digested by an overnight incubation with $100 \mu \mathrm{L}$ of trypsin solution $(10 \mathrm{ng} / \mu \mathrm{L}$, Promega $)$ in $25 \mathrm{mM}$ ammonium bicarbonate buffer at $37^{\circ} \mathrm{C}$. Resulting peptide mixtures were extracted with $50 \%$ acetonitrile in $20 \mathrm{mM}$ ammonium bicarbonate buffer. Finally, they were concentrated with a speed vacuum. The volumes were adjusted to $15 \mu \mathrm{L}$ with $98 \% \mathrm{H}_{2} \mathrm{O}$ solution/2\% acetonitrile $/ 0.05 \%$ trifluoroacetic acid, if the volume was less than $15 \mu \mathrm{L}$ for further analysis by LC-MS/MS.

\subsection{LC-MS/MS Analysis and Identification of Antigens}

The proteins obtained from the immunoprecipitation assays and hydrolyzed by trypsin were submitted to LC-MS/MS analysis. Six microliters of each hydrolysate were injected into the nanoHPLC chain (Ultimate 3000, Dionex, Sunnyvale, CA, USA) on a concentration column to retain the peptides and remove contaminants that could be disruptive in the mass spectrometry analysis. The peptides were then separated according to their hydrophobicity on an analytical column (Acclaim $75 \mu \mathrm{m}, 15 \mathrm{~cm}$ pepmap C18, 2micro $100 \mathrm{~A}$ PN16453, SN10702989). NanoHPLC was coupled to a nanoESI source, a mass-spectrometertype Q-Orbitrap HFX (Thermo Scientific) that operates in data-dependent mode. At the end of the LC-MS/MS analysis, the samples were analyzed in the PROGENESIS QI software (v 4.0, Nonlinear Dynamics). This software allowed both the detection and quantification of all peptide ions detected in the analysis, then the MS/MS analyses performed in the mass spectrometer were interrogated in the Microtus ochrogaster database. As ATS does not have any available databank, Microtus ochrogaster was used due to its phylogenetic proximity. The query engine used was Mascot (V. 2.5.1, internal license version) and Peaks (v10, internal license version). Protein abundance was calculated from the sum of the abundances of the normalized area of each peptide for a specific protein for each run. As the identification was carried out by the Mascot and Peaks software, proteins with high-confidence (FDR $<0.01$ ) were considered as positively identified proteins. These proteomic experiments and analyses were carried out at the INRAe facility (Plateforme d'Exploration du Métabolisme, Composante Protéomique-PFEMcp), Theix, France.

\subsection{Slot Blot Analysis}

The presence of serum IgG directed against the injected peptides was evaluated by slot blot. Increasing quantities of the peptides used for immunization were slotted on nitrocellulose membranes, which were then processed as described above for the Western blot procedure. Pre-immune and immune sera were used after dilution to 1/500 in TBS-T, $2 \% w / v$ BSA.

\subsection{Immunization of Male ATS with Selected Peptides}

Two candidate proteins were chosen to test their ability to trigger a specific immune response in male ATS: CHDH and ZPBP2. The former was chosen because it gave high responses in both males and females, and the latter because it is sperm-specific and involved in gamete interaction (see Table S2). One peptide for each protein was selected based on two main criteria: the species specificity and the potential immunogenicity (depending on their hydrophobicity and on their amino-acid sequence). The chosen sequences remain confidential. Peptides were synthesized (Eurogentec, Seraing, Belgium) and, for each peptide, $500 \mu \mathrm{g}$ were injected subcutaneously in 3 male ATS, as described for whole spermatozoa. A "boost" was made after 3 weeks and the immune sera were collected after 7 weeks (a sample of pre-immune serum was collected for each individual before the first injection). Pre-immune and immune sera were analyzed by slot blot and immunofluorescence.

\subsection{Statistical Analysis}

The maximum fold change ( $\mathrm{mFC}$ ) of proteins detected with male or female immune sera was compared with the $\mathrm{mFC}$ of proteins detected for male or female pre-immune sera. 
The statistical analyses were performed with a Mann-Whitney test performed using the $\mathrm{R}$ software.

\subsection{Bioinformatics}

The protein-protein interaction network for the identified proteins was annotated using the STRING v11 database (recurrent instance search tool for neighboring genes at http:/ / www:/ / string-db.org/ (accessed on 7 July 2020)).

Supplementary Materials: Supplementary Materials can be found at https://www.mdpi.com/ article/10.3390/ijms22189965/s1.

Author Contributions: Conceptualization, J.R.D., F.S. and A.C.; methodology, A.C. and F.S.; software, J.H.-B. and A.C.; validation, A.C., F.S. and J.R.D.; investigation, A.C. and C.G.; data curation, A.C., J.H.-B. and F.S.; writing—original draft preparation, A.C., J.R.D., R.G. and F.S.; writing—review and editing, A.C. and F.S.; supervision, J.R.D. and F.S.; project administration, A.C., J.R.D. and F.S.; funding acquisition, J.R.D. All authors have read and agreed to the published version of the manuscript.

Funding: This research was funded by the European Regional Development Fund (CONTRACAMP) and the Région Auvergne-Rhône-Alpes (CONTRACAMP).

Institutional Review Board Statement: The study was approved by the Auvergne Animal Experiment Ethics Committee (C2E2A) and the French Ministry for Research (APAFIS authorization \# 10653-2017071016422159 v5).

Informed Consent Statement: Not applicable.

Data Availability Statement: All data are presented in figures, tables and supplementary materials.

Acknowledgments: The Conseil Régional d'Auvergne and the FEDER (Fonds européen de dévelop pement regional) financially supported this work. The authors thank S. LAFFONT for the trapping of ATS in the field (FREDON Auvergne: Regional Federation of Defense against Harmful Organisms). The authors also would like to thank Christophe CHAMBON (INRAe, Plateforme d'Exploration du Métabolisme, Composante Protéomique (PFEMcp), U.R.QUAPA, Saint-Genès-Champanelle, France) for his expertise with mass spectrometry analyses. The authors wish to acknowledge the Confocal Microscopy Facility CLIC (Clermont Imagerie Confocale) at Université Clermont Auvergne, Laboratoire iGReD UMR CNRS 6293 INSERM 1103. Finally, the authors thank Yoan RENAUD for sharing his expertise in bioanalysis and statistics (Bioinformatic platform of the iGReD).

Conflicts of Interest: The authors declare no conflict of interest.

\section{References}

1. Airoldi, J.P.; Altrocchi, R.; Meylan, A. Le comportement fouisseur du Campagnol terrestre Arvicola terrestris Scherman Shaw (Mammalia, Rodentia). Rev. Suisse Zool. 1976, 83, 282-286.

2. Berthier, K.; Piry, S.; Cosson, J.F.; Giraudoux, P.; Foltête, J.-C.; Defaut, R.; Truchetet, D.; Lambin, X. Dispersal, landscape and travelling waves in cyclic vole populations. Ecol. Lett. 2014, 17, 53-64. [CrossRef] [PubMed]

3. Saucy, F. Description des cycles pluriannuels d'Arvicola terrestris scherman en Suisse occidentale par la méthode de l'analyse des séries temporelles. EPPO Bull. 1988, 18, 401-413. [CrossRef]

4. Fichet-Calvet, E.; Pradier, B.; Quéré, J.P.; Giraudoux, P.; Delattre, P. Landscape composition and vole outbreaks: Evidence from an eight year study of Arvicola terrestris. Ecography 2000, 23, 659-668. [CrossRef]

5. Giraudoux, P.; Delattre, P.; Habert, M.; Quéré, J.P.; Deblay, S.; Defaut, R.; Duhamel, R.; Moissenet, M.F.; Salvi, D.; Truchetet, D. Population dynamics of fossorial water vole (Arvicola terrestris scherman): A land use and landscape perspective. Agric. Ecosyst. Environ. 1997, 66, 47-60. [CrossRef]

6. Saucy, F. Density dependence in time series of the fossorial form of the water vole, Arvicola terrestris. Oikos 1994, 74, 381-392. [CrossRef]

7. Courant, F.; Brunet-Lecomte, P.; Volobouev, V.; Chaline, J.; Quéré, J.P.; Nadachowski, A.; Montuire, S.; Bao, G.; Viriot, L.; Rausch, R.; et al. Karyological and dental identification of Microtus limnophilus in a large focus of alveolar echinococcosis (Gansu, China). Comptes Rendus Acad. Sci. III 1999, 322, 473-480. [CrossRef]

8. Destrez, A.; Perrot, E.; Granger, S.; Gaillard, C.; Michelin, Y. Les impacts du campagnol terrestre sur les systèmes fourragers: Le cas de l'élevage bovin allaitant en Bourgogne. Fourrages 2014, 220, 291-296.

9. Viel, J.F.; Giraudoux, P.; Abrial, V.; Bresson-Hadni, S. Water vole (Arvicola terrestris scherman) density as risk factor for human alveolar echinococcosis. Am. J. Trop. Med. Hyg. 1999, 61, 559-565. [CrossRef] 
10. Giraudoux, P.; Tremollières, C.; Barbier, B.; Defaut, R.; Rieffel, D.; Bernard, N.; Lucot, É.; Berny, P. Persistence of bromadiolone anticoagulant rodenticide in Arvicola terrestris populations after field control. Environ. Res. 2006, 102, 291-298. [CrossRef]

11. Berny, P.J.; Buronfosse, T.; Buronfosse, F.; Lamarque, F.; Lorgue, G. Field evidence of secondary poisoning of foxes (Vulpes vulpes) and buzzards (Buteo buteo) by bromadiolone, a 4-year survey. Chemosphere 1997, 35, 1817-1829. [CrossRef]

12. Fournier-Chambrillon, C.; Berny, P.J.; Coiffier, O.; Barbedienne, P.; Dassé, B.; Delas, G.; Galineau, H.; Mazet, A.; Pouzenc, P.; Rosoux, R.; et al. Evidence of secondary poisoning of free-ranging riparian mustelids by anticoagulant rodenticides in France: Implications for conservation of European mink (Mustela lutreola). J. Wildl. Dis. 2004, 40, 688-695. [CrossRef]

13. Ruiz-Suarez, N.; Henriquez-Hernandez, L.A.; Valerón, P.F.; Boada, L.D.; Zumbado, M.; Camacho, M.; González, M.A.; Luzardo, O.P. Assessment of anticoagulant rodenticide exposure in six raptor species from the Canary Islands (Spain). Sci. Total Environ. 2014, 485-486, 371-376. [CrossRef] [PubMed]

14. Liu, I.K.; Bernoco, M.; Feldman, M. Contraception in mares heteroimmunized with pig zonae pellucidae. J. Reprod. Fertil. 1989, 85, 19-29. [CrossRef] [PubMed]

15. Kirkpatrick, J.F.; Turner, J.W., Jr.; Liu, I.K.; Fayrer-Hosken, R. Applications of pig zona pellucida immunocontraception to wildlife fertility control. J. Reprod. Fertil. Suppl. 1996, 50, 183-189. [PubMed]

16. Miller, L.A.; Johns, B.E.; Killian, G.J. Long-term effects of PZP immunization on reproduction in white-tailed deer. Vaccine 1999, 18, 568-574. [CrossRef]

17. Moore, H.D.; Jenkins, N.M.; Wong, C. Immunocontraception in rodents: A review of the development of a sperm-based immunocontraceptive vaccine for the grey squirrel (Sciurus carolinensis). Reprod. Fertil. Dev. 1997, 9, 125-129. [CrossRef]

18. Duckworth, J.A.; Buddle, B.M.; Scobie, S. Fertility of brushtail possums (Trichosurus vulpecula) immunised against sperm. J. Reprod. Immunol. 1998, 37, 125-138. [CrossRef]

19. Fayrer-Hosken, R.A.; Grobler, D.; van Altena, J.J.; Bertschinger, H.J.; Kirkpatrick, J.F. Immunocontraception of African elephants. Nature 2000, 407, 149. [CrossRef]

20. Talwar, G.P. Vaccines for control of fertility and hormone-dependent cancers. Immunol. Cell Biol. 1997, 75, 184-189. [CrossRef]

21. Aitken, R.J.; Paterson, M.; Koothan, P.T. Contraceptive vaccines. Br. Med. Bull. 1993, 49, 88-99. [CrossRef]

22. Kerr, L.E.; Paterson, M.; Aitken, R.J. Molecular basis of sperm-egg interaction and the prospects for immunocontraception. J. Reprod. Immunol. 1998, 40, 103-118. [CrossRef]

23. Naz, R.K. Contraceptive vaccines: Success, status, and future perspective. Am. J. Reprod. Immunol. 2011, 66, 2-4. [CrossRef] [PubMed]

24. Naz, R.K. Antisperm contraceptive vaccines: Where we are and where we are going? Am. J. Reprod. Immunol. 2011, 66, 5-12. [CrossRef]

25. Alexander, N.J.; Tung, K.S. Immunological and morphological effects of vasectomy in the rabbit. Anat. Rec. 1977, 188, 339-350. [CrossRef] [PubMed]

26. Ansbacher, R. Sperm-agglutinating and sperm-immobilizing antibodies in vasectomized men. Fertil. Steril. 1971, 22, 629-632 [CrossRef]

27. Tung, K.S.; Alexander, N.J. Immunopathologic studies on vasectomized guinea pigs. Biol. Reprod. 1977, 17, 241-254. [CrossRef]

28. Cyr, D.G.; Finsson, K.; Dufresne, J.; Gregory, M. The Epididymis: From Molecules to Clinical Practice; Robaire, B., Hinton, B.T., Eds.; Springer Science \& Business Media: Berlin/Heidelberg, Germany, 2002; pp. 103-118.

29. McLaughlin, E.A.; Aitken, R.J. Is there a role for immunocontraception? Mol. Cell Endocrinol. 2011, 335, 78-88. [CrossRef]

30. Primakoff, P.; Lathrop, W.; Bronson, R. Identification of human sperm surface glycoproteins recognized by autoantisera from immune infertile men, women, and vasectomized men. Biol. Reprod. 1990, 42, 929-942. [CrossRef]

31. Asquith, K.L.; Kitchener, A.L.; Kay, D.J. Immunisation of the male tammar wallaby (Macropus eugenii) with spermatozoa elicits epididymal antigen-specific antibody secretion and compromised fertilisation rate. J. Reprod. Immunol. 2006, 69, 127-147. [CrossRef]

32. Tung, K.S.; Goldberg, E.H.; Goldberg, E. Immunobiological consequence of immunization of female mice with homologous spermatozoa: Induction of infertility. J. Reprod. Immunol. 1979, 1, 145-158. [CrossRef]

33. Castle, P.E.; Whaley, K.J.; Hoen, T.E.; Moench, T.R.; Cone, R.A. Contraceptive effect of sperm-agglutinating monoclonal antibodies in rabbits. Biol. Reprod. 1997, 56, 153-159. [CrossRef] [PubMed]

34. Grignard, E.; Cadet, R.; Saez, F.; Drevet, J.R.; Vernet, P. Identification of sperm antigens as a first step towards the generation of a contraceptive vaccine to decrease fossorial water vole Arvicola terrestris Scherman proliferations. Theriogenology 2007, 68, 779-795. [CrossRef] [PubMed]

35. Esmailnejad, A.; Nikahval, B.; Mogheiseh, A.; Karampour, R.; Karami, S. The detection of canine anti-sperm antibody following parenteral immunization of bitches against homogenized whole sperm. Basic Clin. Androl. 2020, 30, 1. [CrossRef] [PubMed]

36. Naz, R.K.; Phillips, T.M.; Rosenblum, B.B. Characterization of the fertilization antigen 1 for the development of a contraceptive vaccine. Proc. Natl. Acad. Sci. USA 1986, 83, 5713-5717. [CrossRef]

37. Ellerman, D.A.; Brantúa, V.S.; Martínez, S.P.; Cohen, D.J.; Conesa, D.; Cuasnicú, P.S. Potential contraceptive use of epididymal proteins: Immunization of male rats with epididymal protein DE inhibits sperm fusion ability. Biol. Reprod. 1998, 59, 1029-1036. [CrossRef]

38. Jagadish, N.; Rana, R.; Mishra, D.; Garg, M.; Selvi, R.; Suri, A. Characterization of immune response in mice to plasmid DNA encoding human sperm associated antigen 9 (SPAG9). Vaccine 2006, 24, 3695-3703. [CrossRef] 
39. Wang, M.; Shi, J.L.; Cheng, G.Y.; Hu, Y.Q.; Xu, C. The antibody against a nuclear autoantigenic sperm protein can result in reproductive failure. Asian J. Androl. 2009, 11, 183-192. [CrossRef]

40. Flanagan, K.L.; Fink, A.L.; Plebanski, M.; Klein, S.L. Sex and Gender Differences in the Outcomes of Vaccination over the Life Course. Annu. Rev. Cell Dev. Biol. 2017, 33, 577-599. [CrossRef]

41. Parr, E.L.; Parr, M.B. The effect of sperm immunization in the gastrointestinal tract on anti-sperm antibody production and fertility in female mice. J. Reprod. Immunol. 1986, 9, 49-56. [CrossRef]

42. Tung, K.S.; Harakal, J.; Qiao, H.; Rival, C.; Li, J.C.; Paul, A.G.; Wheeler, K.; Pramoonjago, P.; Grafer, C.M.; Sun, W.; et al. Egress of sperm autoantigen from seminiferous tubules maintains systemic tolerance. J. Clin. Investig. 2017, 127, 1046-1060. [CrossRef]

43. Krämer, A.; Sommer, D.; Hahn, E.G.; Riecken, E.O. German experimental hepatitis B vaccine-Influence of variation of dosage schedule, sex and age differences on immunogenicity in health care workers. Klin. Wochenschr. 1986, 64, 688-694. [CrossRef]

44. Peacock, J.W.; Nordone, S.K.; Jackson, S.S.; Liao, H.-X.; Letvin, N.L.; Yafal, A.G.; Gritz, L.; Mazzara, G.P.; Haynes, B.F.; Staats, H.F. Gender differences in human immunodeficiency virus type 1-specific CD8 responses in the reproductive tract and colon following nasal peptide priming and modified vaccinia virus Ankara boosting. J. Virol. 2004, 78, 13163-13172. [CrossRef]

45. Camus, M.F.; Wolf, J.B.; Morrow, E.H.; Dowling, D.K. Single Nucleotides in the mtDNA Sequence Modify Mitochondrial Molecular Function and Are Associated with Sex-Specific Effects on Fertility and Aging. Curr. Biol. 2015, 25, $2717-2722$. [CrossRef] [PubMed]

46. Ventura-Clapier, R.; Moulin, M.; Piquereau, J.; Lemaire, C.; Mericskay, M.; Veksler, V.; Garnier, A. Mitochondria: A central target for sex differences in pathologies. Clin. Sci. 2017, 131, 803-822. [CrossRef] [PubMed]

47. Freitas, M.J.; Vijayaraghavan, S.; Fardilha, M. Signaling mechanisms in mammalian sperm motility. Biol. Reprod. 2017, 96, 2-12.

48. Paradowska, A.; Bohring, C.; Krause, E.; Krause, W. Identification of evolutionary conserved mouse sperm surface antigens by human antisperm antibodies (ASA) from infertile patients. Am. J. Reprod. Immunol. 2006, 55, 321-330. [CrossRef]

49. Frenette, G.; Girouard, J.; Sullivan, R. Comparison between epididymosomes collected in the intraluminal compartment of the bovine caput and cauda epididymidis. Biol. Reprod. 2006, 75, 885-890. [CrossRef]

50. Girouard, J.; Frenette, G.; Sullivan, R. Comparative proteome and lipid profiles of bovine epididymosomes collected in the intraluminal compartment of the caput and cauda epididymidis. Int. J. Androl. 2011, 34, e475-e486. [CrossRef] [PubMed]

51. Nixon, B.; de Iuliis, G.N.; Hart, H.M.; Zhou, W.; Mathe, A.; Bernstein, I.R.; Anderson, A.L.; Stanger, S.J.; Skerrett-Byrne, D.; Jamaluddin, M.F.B.; et al. Proteomic Profiling of Mouse Epididymosomes Reveals their Contributions to Post-testicular Sperm Maturation. Mol. Cell Proteom. 2019, 18, S91-S108. [CrossRef]

52. Thimon, V.; Frenette, G.; Saez, F.; Thabet, M.; Sullivan, R. Protein composition of human epididymosomes collected during surgical vasectomy reversal: A proteomic and genomic approach. Hum. Reprod. 2008, 23, 1698-1707. [CrossRef]

53. Sullivan, R.; Saez, F. Epididymosomes, prostasomes, and liposomes: Their roles in mammalian male reproductive physiology. Reproduction 2013, 146, R21-R35. [CrossRef]

54. Guiton, R.; Voisin, A.; Henry-Berger, J.; Saez, F.; Drevet, J.R. Of vessels and cells: The spatial organization of the epididymal immune system. Andrology 2019, 7, 712-718. [CrossRef]

55. Hinton, B.T.; Howards, S.S. Permeability characteristics of the epithelium in the rat caput epididymidis. J. Reprod. Fertil. 1981, 63, 95-99. [CrossRef] [PubMed]

56. Huang, Z.; Myers, K.; Khatra, B.; Vijayaraghavan, S. Protein 14-3-3zeta binds to protein phosphatase PP1gamma2 in bovine epididymal spermatozoa. Biol. Reprod. 2004, 71, 177-184. [CrossRef] [PubMed]

57. Saez, F.; Whitfield, M.; Drevet, J.R. Impairment of sperm maturation and capacitation due to diet-dependent cholesterol overload. Andrology 2019, 7, 654-661. [CrossRef] [PubMed]

58. Kawase, O.; Jimbo, M. Detection of sperm-reactive antibodies in wild sika deer and identification of the sperm antigens. J. Vet. Med. Sci. 2018, 80, 802-809. [CrossRef] [PubMed]

59. Petit, F.M.; Serres, C.; Auer, J. Moonlighting proteins in sperm-egg interactions. Biochem. Soc. Trans. 2014, 42, 1740-1743. [CrossRef]

60. Fu, J.; Yao, R.; Luo, Y.; Yang, D.; Cao, Y.; Qiu, Y.; Song, W.; Miao, S.; Gu, Y.; Wang, L. Anti-GAPDHS antibodies: A biomarker of immune infertility. Cell Tissue Res. 2016, 364, 199-207. [CrossRef]

61. Naaby-Hansen, S.; Herr, J.C. Heat shock proteins on the human sperm surface. J. Reprod. Immunol. 2010, 84, 32-40. [CrossRef]

62. Agarwal, A.; Selvam, M.K.P.; Samanta, L.; Vij, S.C.; Parekh, N.; Sabanegh, E.; Tadros, N.N.; Arafa, M.; Sharma, R. Effect of Antioxidant Supplementation on the Sperm Proteome of Idiopathic Infertile Men. Antioxidants 2019, 8, 488. [CrossRef]

63. Lin, Y.N.; Roy, A.; Yan, W.; Burns, K.H.; Matzuk, M.M. Loss of zona pellucida binding proteins in the acrosomal matrix disrupts acrosome biogenesis and sperm morphogenesis. Mol. Cell Biol. 2007, 27, 6794-6805. [CrossRef] [PubMed]

64. Asquith, K.L.; Harman, A.J.; McLaughlin, E.A.; Nixon, B.; Aitken, R.J. Localization and significance of molecular chaperones, heat shock protein 1, and tumor rejection antigen gp96 in the male reproductive tract and during capacitation and acrosome reaction. Biol. Reprod. 2005, 72, 328-337. [CrossRef] [PubMed]

65. Nowicka-Bauer, K.; Kamieniczna, M.; Cibulka, J.; Ulcova-Gallova, Z.; Kurpisz, M. Proteomic identification of sperm antigens using serum samples from individuals with and without antisperm antibodies. Andrologia 2016, 48, 693-701. [CrossRef]

66. Fiedler, S.E.; Bajpai, M.; Carr, D.W. Identification and characterization of RHOA-interacting proteins in bovine spermatozoa. Biol. Reprod. 2008, 78, 184-192. [CrossRef]

67. Suri, A. Contraceptive vaccines targeting sperm. Expert Opin. Biol. Ther. 2005, 5, 381-392. [CrossRef] [PubMed] 